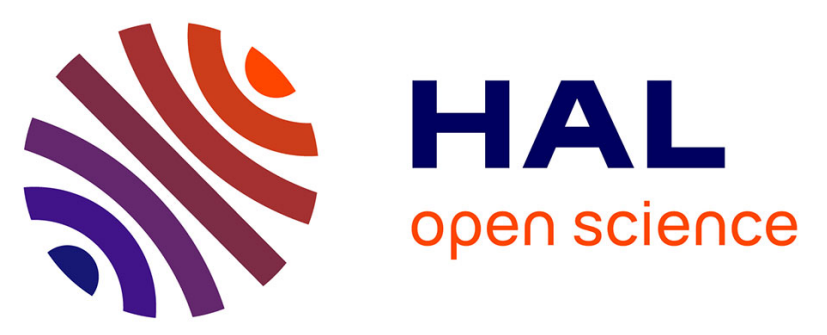

\title{
LMNA mutations resulting in lipodystrophy and HIV protease inhibitors trigger vascular smooth muscle cell senescence and calcification: Role of ZMPSTE24 downregulation
}

\author{
Pauline Afonso, Martine Auclair, Franck Boccara, Marie-Christine \\ Vantyghem, Christine Katlama, Jacqueline Capeau, Corinne Vigouroux, \\ Martine Caron-Debarle
}

\section{- To cite this version:}

Pauline Afonso, Martine Auclair, Franck Boccara, Marie-Christine Vantyghem, Christine Katlama, et al.. LMNA mutations resulting in lipodystrophy and HIV protease inhibitors trigger vascular smooth muscle cell senescence and calcification: Role of ZMPSTE24 downregulation. Atherosclerosis, 2016, 245, pp.200-211. 10.1016/j.atherosclerosis.2015.12.012 . hal-01286022

\section{HAL Id: hal-01286022 \\ https: / hal.sorbonne-universite.fr/hal-01286022}

Submitted on 10 Mar 2016

HAL is a multi-disciplinary open access archive for the deposit and dissemination of scientific research documents, whether they are published or not. The documents may come from teaching and research institutions in France or abroad, or from public or private research centers.
L'archive ouverte pluridisciplinaire HAL, est destinée au dépôt et à la diffusion de documents scientifiques de niveau recherche, publiés ou non, émanant des établissements d'enseignement et de recherche français ou étrangers, des laboratoires publics ou privés. 


\title{
LMNA mutations resulting in lipodystrophy and HIV protease inhibitors trigger vascular smooth muscle cell senescence and calcification: role of ZMPSTE24 downregulation
}

\author{
Pauline Afonso $^{\mathrm{a}}$, Martine Auclair ${ }^{\mathrm{b}}$, Franck Boccara ${ }^{\mathrm{c}}$, Marie-Christine Vantyghem ${ }^{\mathrm{d}}$, Christine \\ Katlama $^{\mathrm{e}}$, Jacqueline Capeau ${ }^{\mathrm{f}}$, Corinne Vigouroux ${ }^{\mathrm{g}}$, Martine Caron-Debarle ${ }^{\mathrm{h}}$
}

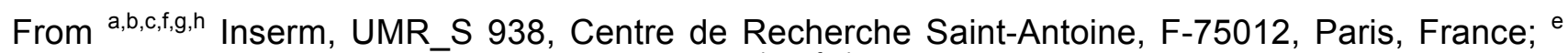
Inserm UMR S 1136, F-75013 Paris, France; a,b,c,e,f,g,h Sorbonne Universités, UPMC Univ Paris 06, F-75005, Paris, France; ${ }^{c}$ AP-HP, Hôpital Saint-Antoine, Service de Cardiologie and ${ }^{9}$ Laboratoire Commun de Biologie et Génétique Moléculaires, F-75012, Paris, France; ${ }^{f}$ AP-HP, Hôpital Tenon, Service de Biochimie et Hormonologie, F-75020 Paris, France; ${ }^{d}$ Centre Hospitalier Régional Universitaire de Lille, Service d'Endocrinologie et Métabolisme, F-59037 Lille, France; ${ }^{\text {e AP-HP, }}$ Hôpital de la Pitié-Salpêtrière, Service des Maladies Infectieuses et Tropicales, F-75013 Paris; a,b,f,g,h ICAN, Institute of Cardiometabolism and Nutrition, F-75013, Paris, France

Correspondance to Corinne Vigouroux, INSERM UMR_S 938, Faculté de Médecine site Saint Antoine, 27 rue Chaligny, F-75012, Paris, France. corinne.vigouroux@inserm.fr Tel: +33140011484; Fax: +33140011432

E-mail addresses of all the authors:

Pauline Afonso: pauline.afonso@gmail.com Martine Auclair: martine.auclair@inserm.fr Franck Boccara: franck.boccara@aphp.fr Marie-Christine Vantyghem: marie-christine.vantyghem@chru-lille.fr Christine Katlama: christine.katlama@aphp.fr Jacqueline Capeau: jacqueline.capeau@inserm.fr Martine Caron-Debarle: martine.debarle@inserm.fr 


\begin{abstract}
Background: Some LMNA mutations responsible for lipodystrophies, and some HIV-protease inhibitors (PIs) induce accumulation of farnesylated prelamin A and premature senescence in some cell types. Patients with LMNA mutations or under PI-based therapy suffer from early atherosclerosis. The metalloprotease ZMPSTE24 is the key enzyme in prelamin A maturation.
\end{abstract}

Aim: We studied whether altered expression of ZMPSTE24 could contribute to vascular cell dysfunction in response to LMNA mutations or PI treatments.

Methods: Protein expression of prelamin A and ZMPSTE24 were evaluated in patients' cells and in human cultured VSMCs. Oxidative stress, inflammation, senescence and transdifferentiation/calcification were evaluated in VSMCs.

Results: Fibroblasts from LMNA-mutated lipodystrophic patients (mutations R482W, D47Y or $\mathrm{R} 133 \mathrm{~L}$ ) and peripheral blood mononuclear cells from PI-treated-HIV-infected patients expressed increased prelamin A and decreased ZMPSTE24, which was also observed in VSMCs overexpressing mutant $\angle M N A$ or treated with PIs. These alterations correlated with oxidative stress, inflammation, senescence and calcification (all $p<0.05$ ). ZMPSTE24 silencing in native VSMCs recapitulated the mutant $\angle M N A$ - and $\mathrm{Pl}$-induced accumulation of farnesylated prelamin $\mathrm{A}$, oxidative stress, inflammation, senescence and calcification. A negative regulator of ZMPSTE24, miRNA141-3p, was enhanced in LMNA-mutated or PI-treated VSMCs. The farnesylation inhibitors pravastatin and $\mathrm{FTI}-277$, or the antioxidant $\mathrm{N}$-acetyl cysteine, partly restored ZMPSTE24 expression, and concomitantly decreased oxidative stress, inflammation, senescence, and calcification of PI-treated VSCMs.

Conclusions: ZMPSTE24 downregulation is a major contributor in VSMC dysfunctions resulting from LMNA mutations or PI treatments that could translate in early atherosclerosis at the clinical level. These novel pathophysiological mechanisms could open new therapeutic perspectives for cardiovascular aging. 
Key Words: Vascular smooth muscle cells, ZMPSTE24, prelamin A, senescence, osteogenic transdifferentiation, atherosclerosis

\section{Abbreviations}

$\begin{array}{ll}\text { ALP } & \text { alkaline phosphatase } \\ \text { ATV } & \text { atazanavir } \\ \text { DRV } & \text { darunavir } \\ \text { HIV } & \text { human immunodeficiency virus } \\ \text { LPV } & \text { lopinavir } \\ \text { M/R } & \text { maraviroc/raltegravir } \\ \text { PBMCs } & \text { peripheral blood mononuclear cells } \\ \text { PIs } & \text { protease inhibitors } \\ \text { ROS } & \text { reactive oxygen species } \\ \text { RTV or r } & \text { ritonavir } \\ \text { Runx2 } & \text { runt-related transcription factor } 2 \\ \text { VSMCs } & \text { vascular smooth muscle cells }\end{array}$




\section{Introduction}

A-type lamins are intermediate filaments of the nuclear lamina, a filamentous network located below the inner nuclear membrane and required for structural and functional integrity of the nucleus. Atype lamins interact with B-type lamins at the nuclear envelope, as well as to heterochromatin and transcriptional regulators, highlighting their important role in chromatin organization, gene expression, and DNA repair. Alternative splicing of the $L M N A$ gene gives rise to two main A-type lamin isoforms, prelamin $A$ and lamin $C$. Prelamin A undergoes a complex post-translational maturation, initiated by the addition of a farnesyl moiety to the last cysteine residue of the protein. After several steps, removal of the carboxymethylated C-terminal of the protein, including its farnesyl group, by the metalloprotease ZMPSTE24, results in the release of mature nonfarnesylated lamin A [1].

Several studies have shown the cellular toxicity of accumulated prelamin A, pointing to the role of the retained farnesyl group, which alters the binding properties of the partially processed prelamin $\mathrm{A}$ to several partners [2-4]. Persistent farnesylation of prelamin $A$ has been involved in premature cellular senescence associated with several diseases. This is the case in premature ageing syndromes as Hutchinson-Gilford progeria (HGPS) due to mutations in LMNA or ZMPSTE24 [5-9], but also in LMNA-related progeroid and/or lipodystrophic syndromes [10, 11].

Mutations in LMNA and accumulation of farnesylated prelamin A are cardinal features of typical premature aging diseases, but also of progeroid syndromes and Familial Partial Lipodystrophy of the Dunnigan type (FPLD), all these conditions being associated with early atherosclerosis and cardiovascular events [12-15]. In addition, altered lamin A maturation could be involved in agerelated atherosclerotic cardiovascular diseases in the general population. Indeed, prelamin $A$ accumulates in the arterial wall during physiological aging, and colocalizes with degenerating and senescent vascular smooth muscle cells (VSMCs) into atherosclerotic lesions, a defect in part attributed to ZMPSTE24 downregulation [16, 17].

Human immunodeficiency virus-1 (HIV)-infected patients display an increased cardiovascular risk, attributed to multiple synergic factors including the therapeutic use of some antiretrovirals belonging to the class of HIV protease inhibitors (PIs), which target the HIV aspartyl protease [18-20]. Interestingly, it has been previously shown that some of these Pls, including lopinavir and atazanavir, and to a lesser extent darunavir, can directly inhibit ZMPSTE24 activity and induce cellular prelamin A accumulation [10, 21-23]. In addition, PI-induced farnesylated prelamin A accumulation was associated with cellular dysfunction and senescence in several cellular models [10, 24-26]. Until now the potential role of ZMPSTE24 deregulation in LMNA-mutated and PI-treated patients, which could participate to their premature vascular aging, has never been investigated. 
VSMCs contribute to the initiation of atherosclerosis by transdifferentiating into osteoblast/chondrocyte-like cells. This process results, amongst other factors, from the activation of osteoblastic transcription factors, like Runx2, and from oxidative and inflammation pathways [2729]. Calcification of VSMCs, associated with premature senescence [30], could lead to arterial calcification and stiffening [31] as observed in patients with HGPS and LMNA-linked progeroid syndromes [12, 14]. Coronary artery calcium score, a marker of vascular age and subclinical atherosclerosis [32], is increased in HIV-infected patients [33, 34], and long-term antiviral therapy including PIs is associated with vascular calcification [33, 35, 36].

Therefore, the objective of our study was to explore the potential link between ZMPSTE24 deregulation and the development of VSCM dysfunctions in response to LMNA mutations and PItreatments.

We show, for the first time, that prelamin A accumulation observed in cells from patients harboring FPLD or progeroid syndromes-associated LMNA mutations, or treated with long-term PI-based HIV antiretrovirals, was associated with ZMPSTE24 downregulation. We then revealed in cultured VSMCs that overexpression of these LMNA mutations or long-term exposure to ritonavir ( $\mathrm{r}$ )-boosted PIs lopinavir (LPV) or atazanavir (ATV), also induced ZMPSTE24 downregulation together with triggering senescence and associated dysfunctions to different extents, resulting in osteoblastic conversion. These results, showing that ZMPSTE24 downregulation play a major role in the proatherosclerotic alterations of VSCMs, suggest novel pathophysiological mechanisms linking lipodystrophy-associated $L M N A$ mutations and PI exposure to precocious cardiovascular diseases.

\section{Material and methods}

\subsection{Cell culture and treatment}

Human coronary artery vascular smooth muscle cells (or VSMCs) were obtained from middle-aged healthy donors (PromoCell, Heidelberg, Germany) and cultured from passages 2 to 8 . The cells were either transfected with void, wild-type (WT) or mutant LMNA expression vectors, or exposed for 21 days to clinically relevant concentrations (Cmax) of protease inhibitor (PI) combinations (LPV/r, 15.9/1.4; ATV/r, 7.4/1.3 or DRV/r 11.8/0.8 $\mu \mathrm{mol} / \mathrm{L}$, respectively) (Santa Cruz Biotechnology, CA) [26], or to the solvent ( $0.1 \%$ dimethyl sulfoxide, DMSO). The farnesyl moiety synthesis inhibitor pravastatin $(25 \mu \mathrm{mol} / \mathrm{L})$, the farnesyl transferase inhibitor FTI-277 $(20 \mu \mathrm{mol} / \mathrm{L})$, the antioxydant $\mathrm{N}$ acetyl cysteine (NAC, $1 \mathrm{mmol} / \mathrm{L})$ or anti-calcifying agent etidronate disodium hydrate $(4 \mu \mathrm{mol} / \mathrm{L})$ were added along the PI exposure (pravastatin and etidronate) or for the last 3 days (FTI-277), 4 days (NAC) or 10 days (etidronate), respectively. 


\subsection{Patients with LMNA mutations or HIV infection}

We studied different heterozygous LMNA mutations, which substituted arginine to tryptophan at codon 482 (R482W), leading to Familial Partial Lipodystrophy of Dunnigan (FPLD), or aspartate 47 to tyrosine (D47Y) or arginine 133 to lysine (R133L) leading to atypical progeroid syndromes [10, 12]. Patients harboring these mutations presented with lipodystrophy, insulin resistance, dyslipidemia, liver steatosis and premature atherosclerosis [10, 12, 15]. Primary skin fibroblast cultures were established after plastic surgery in four healthy controls (non-obese, non-diabetic) or after punch biopsy in patients with LMNA R482W ( $n=6)$ [37], D47Y $(n=1)$ [10] or R133L $(n=1)$ [12] mutations. All the subjects gave their written informed consent for these studies.

HIV-infected patients participated to the ANRS157 ROCnRAL study [38]. At inclusion, five patients (median age: 57 +/- 9 years) on long-term antiretroviral therapy with suppressed viremia were switched to a regimen combining a CCR5-receptor antagonist (maraviroc) and an integrase inhibitor (raltegravir). Peripheral blood mononuclear cells (PBMCs) were collected at enrollment and after 4 months of maraviroc/raltegravir (M/R) therapy. Proteins were extracted as described [24] and the level of prelamin A and ZMPSTE24 were quantified by Western blotting.

\subsection{Transfection assays of LMNA mutants}

Flag-tagged wild-type (WT) and D47Y-, R133L- and R482W-mutated prelamin A cDNA were cloned in pSVK3 to yield WT or mutant lamin A expression vectors (GeneCust, Dudelange, Luxembourg). VSMCs were transfected with WT or mutant LMNA vectors $(0.8 \mu \mathrm{g})$ using PolyFect transfection reagent (Qiagen, Courtaboeuf, France), and studied 7 days later. Transfection efficiency was evaluated by using anti-Flag M5 antibodies (Sigma-Aldrich, Saint Quentin-Fallavier, France). Control cells were incubated with transfection reagent only.

\subsection{Cell morphology and immunofluorescence microscopy}

VSMCs were fixed in methanol and incubated with antibodies against alpha-smooth muscle (a-SM)actin (A5228, Sigma-Aldrich), phospho-histone y-H2AX (Ser 139) (05-636, Merck Millipore, Billerica $\mathrm{MA}$ ), and prelamin A (sc-6214, Santa Cruz Biotechnology) and visualized by immunofluorescence microscopy [10]. Cell nuclei were stained with DAPI. For each condition, 100 to 150 cells were examined.

\subsection{Western blotting}

Cell lysates were subjected to SDS-PAGE and Western blotting. Antibodies previously described $[10,26]$ or directed against osteocalcin (sc-18319, Santa Cruz Biotechnology), ZMPSTE24 (AP24156, Abgent.Inc, San Diego, CA), Runt-related transcription factor-2 (Runx2, AF-2006, R\&D 
Systems, Minneapolis, MN), $\alpha$-tubulin (T5168) or $\beta$-actin (A5441) (Sigma-Aldrich) were detected with a chemoluminescence detection kit (ThermoFischer Scientific, Villebon sur Yvette, France).

The antibodies sc-7292 recognizes lamin A/C and prelamin A, and sc-6214 recognizes prelamin A (Santa Cruz Biotechnology).

Western blot quantification data were performed in triplicate using Fiji software. Results from three independently performed experiments were used.

\subsection{Oxidative stress and inflammation}

ROS production was measured by nitroblue tetrazolium (NBT, Sigma-Aldrich) reduction and by CM$\mathrm{H}_{2}$ DCFDA derivatives (C6827, Molecular Probes) oxidation as described [24]. Inflammation was determined by the protein expression of the phosphorylated form (serine 536) of NF-kB p65/RelA subunit and by the mRNA expression of the pro-inflammatory cytokines, interleukin-33 (IL-33), IL-6 and MCP-1. The mRNA level of the anti-inflammatory cytokine IL-13 has also been determined.

\subsection{Senescence}

Senescence was evaluated by the senescence-associated (SA)- $\beta$-galactosidase activity (X-gal staining at $\mathrm{pH}-6 / \mathrm{pH}-4)$, the presence of $\mathrm{y}-\mathrm{H} 2 \mathrm{AX}$-associated foci, and the protein expression of the senescence markers $\mathrm{p} 16^{\mathrm{INK} 4}, \mathrm{p} 21^{\mathrm{WAF}}$, phospho-p53, prelamin A, and ZMPSTE24 as described [10, $16,24,26]$. Altered cell morphology was also considered as a senescence marker.

\subsection{Transdifferentiation and calcification}

Osteoblastic transdifferentiation was evaluated by the protein expression of the osteogenic markers osteocalcin and Runx2, and the enzymatic activity of alkaline phosphatase (ALP, kit B5655, Sigma Aldrich). Calcium deposition was evaluated after Alizarin Red S (Sigma-Aldrich) staining and measured by spectrophotometry at $415 \mathrm{~nm}$ and by phase contrast microscopy.

\section{9. $m R$ RA silencing}

VSMCs were incubated 6 hours with 100 pmoles of a pool of three target-specific human siRNA for ZMPSTE24 (FACE1, SC-45524, Santa Cruz Biotechnology) or Runx2 (SC-37145) or scrambled siRNA (SC-37007) in transfection reagent. Cells markers were evaluated 7-days later.

\subsection{Reverse-Transcription and Real-Time quantitative PCR}

Total RNA was extracted using the RNeasy mini kit (74104, Qiagen). The QuantiTect Primer Assay was used for detection of IL-13, IL-33, IL-6 and MCP-1 mRNA (Qiagen). The miScript PCR system was used for detection of the miR-141-3p (miScript II RT and miScript SYBR Green PCR kits). RTqPCR assays were performed in triplicate on the LightCycler ${ }^{\circledR} 480$ System (Roche). The cycle number at which the amount of amplified target reaches a fixed threshold (CT) was determined. The 
expression level of samples were normalized to the housekeeping gene GAPDH or miScript PCR controls (Qiagen).

\subsection{Statistical analysis}

All experiments were performed at least four times on triplicate samples. Quantitative results were expressed as means \pm SEM. Statistical analyses were performed using the GraphPad Prism version 5.0c (GraphPad Software, La Jolla, CA). Comparison between groups used the nonparametric Mann-Whitney test. $P$ values were considered significant when less than 0.05 .

\section{Results}

3.1. Defective ZMPSTE24 protein expression is observed in cells from patients with LMNA mutations or under PI-based HIV therapy, and in VSMCs expressing mutated LMNA or treated with PIs.

We initially evaluated the protein expression of ZMPSTE24 in fibroblasts from LMNA-mutated patients, and in PBMCs from HIV-infected patients under PI-based therapy. As expected, prelamin A markedly increased in fibroblasts from patients bearing the D47Y, R133L or R482W LMNA mutations, and in PBMCs from PI-treated patients (Fig.1A). In these patients' cell lysates, the protein expression of ZMPSTE24 was markedly altered. In patients' PBMCs, ZMPSTE24 expression was minimal in patient 1 receiving LPV/r, intermediate in patients 2 and 3 receiving $\mathrm{DRV} / \mathrm{r}$, and maximal in patient 4 on DRV/r and in patient 5 treated without PI. Interestingly, when the therapy of the patients 1 to 3 was switched to maraviroc/raltegravir (M/R), the levels of prelamin $A$ and ZMPSTE24 almost returned to values similar to those observed in patients 4 and 5 (Fig.1A).

The heterozygous LMNA mutations $\mathrm{D} 47 \mathrm{Y}, \mathrm{R} 133 \mathrm{~L}$ and $\mathrm{R} 482 \mathrm{~W}$, and some $\mathrm{Pl}$-based therapies are clinically associated with premature atherosclerotic disease and vascular calcification (Fig.S1A) [12, 15, 18-20]. To more directly approach the role of ZMPSTE24 in these vascular disorders, we used cultured human vascular smooth muscle cells, either overexpressing the same LMNA mutations or treated for long-term with damaging PI combinations.

Three Flag-tagged mutants, D47Y, R133L, or R482W and wild-type (WT) prelamin A were ectopically expressed in cultured human VSMCs (Fig.1B). Anti-Flag antibodies indicated that 40$60 \%$ of VSMCs were efficiently transfected, expressing almost similar levels of WT and/or mutant lamin A (Fig.1B, S1B and immunofluorescence microscopy, data not shown), thus reproducing the heterozygous state of patients' cells. As expected, mutant, but not WT, LMNA-transfected VSMCs showed increased percentage of prelamin A positive cells $(55-70 \%$ versus $9 \%$, data not shown, 100-150 cells for each condition). As observed in patients' cells, the increased protein level of 
prelamin A correlated with a decrease in that of ZMPSTE24 (Fig.1B). Accordingly, a 21-day treatment with $L P V / r$ and $A T V / r$, but not $D R V / r$, induced prelamin $A$ accumulation, and severely decreased ZMPSTE24 expression (Fig.1B).

Taken together these results indicated that defective ZMPSTE24 expression might play a role in altered lamin A maturation observed in lipodystrophic patients bearing LMNA mutations or under PIbased therapy.

\subsection{Altered lamin A processing correlated with human vascular cell dysfunctions}

Defective ZMPSTE24 expression in LMNA-mutated or PI-treated VSMCs was associated with oxidative stress and inflammation (Fig.2A,B). Overexpression of LMNA mutations markedly increased ROS production evaluated by NBT reduction (2.6- to 2.8-fold increase) (Fig.2A). PItreated VSMCs also displayed an increased level of oxidative stress. NBT reduction was enhanced to different extents according to the PI combination, by 4.8-, 2.5- and 1.7-fold in response to LPV/r, ATV/r and DRV/r, whereas oxidation of $\mathrm{CM}-\mathrm{H}_{2}$ DCFDA derivatives increased by 9.6-, 5.5- and 2-fold, respectively (Fig.2A).

LMNA mutations also promoted inflammation as indicated by the altered level of phosphorylatedp65RelA NF-кB subunit (Fig.2B, S1C), and of mRNA expression of a series of inflammatory cytokines. IL-33, IL-6 and MCP-1 increased by 7 - to 18-fold in cells bearing the mutations D47Y and R482W, whereas the anti-inflammatory cytokine IL-13 decreased by 2-fold (Fig.2B). The mRNA expression of IL-33, IL-6 and MCP-1 was significantly increased by the R133L mutation, but at a lower level (1.7-to 3-fold). As well, the mRNA secretion of inflammatory cytokines was significantly increased by LPV/r long-term treatment (Fig.2B). LPV/r and ATV/r, and to a lesser extent DRV/r, also increased the level of phosphorylated-p65/RelA NF-kB subunit (Fig.2B, S1C).

We, and others, previously reported that the altered maturation of prelamin A correlated with the setup of a cellular senescence program [10,15, 16, 24]. We thus tested senescence markers in LMNA-mutated or PI-treated VSMCs and observed that SA-ß-galactosidase activity was increased by 2.2- to 2.5-fold in LMNA mutant versus WT, and by 3- to 4-fold in LPV/r- and ATV/r-treated cells versus DMSO (Fig.2C). The protein expression of the senescence markers, p16 ${ }^{\mathrm{INK} 4}$, p2 ${ }^{\mathrm{WAF}}$, p53 and phospho-p53 was also altered (Fig.2C, S1D). LPV/r had a stronger effect than ATV/r and DRV/r (4-fold versus 3-fold and 1.5-fold increase in SA-ß-galactosidase activity, respectively, as compared to DMSO). LMNA mutant or LPV/r-treated VSMCs harbored the typical morphology of senescent cells, with an increased number of prelamin A-stained nuclei showing dysmorphies, and of foci containing phosphorylated histone $\mathrm{y}-\mathrm{H} 2 \mathrm{AX}$ indicating DNA damages (data not shown and Fig.2C). 
Thus, downregulation of ZMPSTE24 observed in VSMCs bearing lipodystrophy-linked LMNA mutations or treated with Pls correlated with cellular dysfunctions including oxidative stress and inflammation, leading to premature senescence.

\subsection{LMNA mutations and PI treatments induce osteogenic transdifferentiation of VSMCs}

To go further into the impact of LMNA mutations and PI long-term treatment in VSMCs, we tested markers of transdifferentiation and calcification, two ultimate steps of VSMC alteration in the atherosclerosis process [39]. Overexpression in human VSMCs of mutant LMNA, but not WT, enhanced the osteoblastic markers Runx2 and osteocalcin (Fig.3A, S1E), and the activity of alkaline phosphatase (ALP) (1.9- to 2.3-fold increase), as well as cell mineralization (2.9- to 3.6-fold increase in alizarin red staining) (Fig.3B-C). PI-treated VSMCs exhibited similar features of osteogenic transdifferentiation leading to calcification (Fig.3A-C, S1E). The effect of LPV/r or ATV/r was more pronounced than that of $\mathrm{DRV} / \mathrm{r}$ (only significant for alizarin staining). Osteoblastic transition was also shown by the disorganization of the $\alpha$-smooth muscle (SM)-actin network in prelamin-A positive LPV/r-treated VSMCs, contrasting with well-organized fibers of control cells (Fig.3D).

\subsection{ZMPSTE24 downregulation plays a major role in VSMC dysfunction}

We then checked whether ZMPSTE24 knock-down by specific siRNA could reproduce in native VSMCs the effect of LMNA mutations or PI treatments.

As expected, ZMPSTE24 silencing decreased ZMPSTE24 protein expression and induced prelamin A accumulation in control VSMCs (Fig.4A, S2A). In these cells, oxidative stress (4.1-fold increase in NBT reduction) and inflammation (increased expression of phosphorylated-p65/RelA NF- $\kappa B$ subunit) (Fig.4A, S2A) were markedly increased, together with the senescence markers, SA-ßgalactosidase activity (2.7-fold increase as compared to scramble-transfected cells), p16 ${ }^{\text {INK4 }}$, p2 $1^{\text {WAF }}$ and p-p53/p53 expression (Fig.4B, S2B). ZMPSTE24 knockdown also triggered osteogenic transdifferentiation, as shown by increased osteocalcin and Runx2 levels, ALP activity (2.6-fold) and alizarin red staining (3.1-fold) (Fig.4C, S2B).

These results confirmed that the modulation of ZMPSTE24 negatively affected the vascular cells and reinforce the hypothesis that ZMPSTE24 plays a role in adverse effects of LMNA mutations or Pl-treatments.

The data lead us to investigate the mechanism whereby LMNA mutations or PI treatments could alter ZMPSTE24 expression. We first evaluated the expression of miR-141-3p, which was shown by $\mathrm{Yu}$ et al. to regulate ZMPSTE24 protein expression during cellular senescence [40]. The level of miR-141-3p was increased by 1.5-fold in VSMCs expressing D47Y and R482W LMNA mutant and 
by 2-fold in LPV/r-treated cells, as compared to control cells (Fig.4D). As ZMPSTE24 mRNA level did not vary in VSMCs expressing LMNA mutations or treated with LPV/r (data not shown, $\mathrm{n}=5$ ), miR-141-3p probably altered ZPMSTE24 translation rather than transcript stability, as shown for other miRNAs [41].

\subsection{Pravastatin, FTI-277 and N-acetyl cysteine rescue ZMPSTE24 downregulation in LMNA- transfected or PI-treated cells}

To go further into the mechanisms involved in ZMPSTE24 downregulation, we used a series of pharmacological molecules to decrease farnesylation of prelamin A or oxidative stress in our model. We previously observed that pravastatin, which inhibits the synthesis of the farnesyl moiety, and FTI-277, a farnesyl transferase inhibitor, can, at least in part, prevent or revert the cellular toxicity of prelamin $A[10,15,24]$. As expected from their capacity to block the first step of the prelamin $A$ maturation process, pravastatin and FTI-277 induced the accumulation of prelamin $A$ in control, LMNA-mutated and LPV/r-exposed VSMCs (Fig.5A,B, S3A, S4A). The altered electrophoretic mobility of the farnesylation indicator HDJ-2 (Fig.S3B), indicated that protein farnesylation was efficiently inhibited, suggesting that accumulated prelamin A was not farnesylated (Fig.5A). Importantly, pravastatin partly prevented ZMPSTE24 downregulation induced by LMNA mutations or LPV/r (Fig.5A \& S3A,B). Pravastatin also improved oxidative stress (1.5-2-fold decrease), inflammation (Fig.5A), and senescence markers, (SA-ß-galactosidase activity (1.2- versus 2.9- to 6fold), p16 ${ }^{\mathrm{INK} 4}$ and $\mathrm{p} 21^{\mathrm{WAF}}$ ) (Fig.S3A,B) in LMNA-mutated or PI-treated VSMCs. Finally, pravastatin prevented LMNA mutation- or LPV/r-induced osteogenic transdifferentiation, as assessed by Runx2 and osteocalcin expression, ALP activity and calcium deposition (Fig.S3A,B).

Interestingly, the effects were similar when $\mathrm{FTI}-277$ was added during the last $72 \mathrm{~h}$ of $\mathrm{LPV} / \mathrm{r}$ treatment. FTI-277 partly prevented ZMPSTE24 downregulation, and decreased the effect of LPV/r on oxidative stress, inflammation, senescence, and calcification/transdifferentiation (Fig.5B, S4).

Thus, the cellular toxicity associated with farnesylated prelamin A accumulation could play a role in ZMPSTE 24 downregulation.

We and others previously observed that decreasing the cellular oxidative stress by anti-oxidants had beneficial effect on the adverse effect elicited by LMNA mutations or PI treatment [10, 15, 24]. Adding the antioxidant $\mathrm{N}$-acetyl cysteine (NAC) for the last 4 days of LPV/r treatment decreased oxidative stress in VSMCs as expected (Fig.5C). Importantly, NAC partly normalized the protein levels of ZMPSTE24 (Fig.5C, S5A). The markers of inflammation (NF-kB activation), senescence (p16 $6^{\text {INK4 }}$ and $\mathrm{p} 21^{\mathrm{WAF}}$ and SA-galactosidase activity by $50 \%$ ), and calcification (alizarin red staining by $70 \%$ ) also decreased in LPV/r treated VSMCs in the presence of NAC (Fig.5C, S5). 
Taken together, these results indicated that increased oxidative stress could participate to ZMPSTE24 downregulation in cells accumulating farnesylated prelamin A.

\subsection{Inhibition of calcification does not affect the LPV/r-induced senescence program and ZMPSTE24 expression}

Finally, we studied the consequences of a direct inhibition of calcification in PI-treated VSMCs, by using Runx2 siRNA-mediated silencing or the anti-calcifying agent, etidronate. Importantly, etidronate, unlike other bisphosphonates, suppresses osteoclastic activity without impacting the mevalonate pathway [42], and thus does not interfere by itself with the farnesylation processes implicated in prelamin A maturation.

Runx2 silencing or co-treatment with etidronate decreased osteogenic markers and calcium deposition in LPV/r-treated VSMCs, as assessed by osteocalcin and Runx2 levels, ALP activity (1.2- versus 3-fold), and alizarin red staining (2.3-versus 10-fold) (Fig.S6A). When etidronate was added after the initiation of the calcification process (from day 11 to day 21 of LPV/r treatment), a two-fold decrease in osteogenic markers was observed at day 21 (data not shown), consistent with an arrest of the still-engaged mineralization process.

Runx2 knockdown or co-treatment with etidronate partially inhibited LPV/r-induced ROS production (by $50-60 \%$ ) and weakly altered the inflammation status (Fig.S6B). Moreover, they failed to affect the senescence markers ( $\mathrm{p} 16^{\mathrm{INK} 4}, \mathrm{p} 21^{\mathrm{WAF}}$ and SA-ß-galactosidase activity) and did not modify the level of prelamin A and ZMPSTE24 (Fig.S6C).

Therefore, an efficient inhibition of VSCM calcification was unable to prevent Pl-induced senescence, further pointing to the initiating role of ZMPSTE24 downregulation and prelamin A accumulation in the cellular dysfunctions leading to the activation of the senescence program and finally resulting in vascular calcification.

\section{Discussion}

Our study demonstrated for the first time in cells from patients with LMNA mutations or under HIV PI therapy that persistent accumulation of prelamin A is associated with downregulation of ZMPSTE24. We also observed in human VSMCs that ectopic expression of mutant LMNA (D47Y, R133L or $\mathrm{R} 482 \mathrm{~W}$ ) or long-term treatment with some PI combinations (LPV/r, ATV/r), all previously associated with farnesylated prelamin A accumulation [10, 15, 24, 26, 43, 44], also promote ZMPSTE24 downregulation together with vascular cell dysfunctions, including oxidative stress, inflammation, senescence and transdifferentiation/calcification. This could provide a pathophysiological basis for 
the early atherosclerotic and/or calcified plaques observed in patients bearing LMNA mutations responsive for syndromes of lipodystrophy and/or premature aging $[12,14,15]$ and in those with HIV infection receiving PI-based therapy $[18,20,33,35,36]$.

The impact of the three tested LMNA mutations on VSMCs dysfunctions was almost similar, although LMNA R133L showed milder effects on two points, i.e. interleukin expression and miR141-3p level. The mutations affect different lamin A/C protein domains, i.e. the central dimerization coiled-coiled domain for mutations D47Y and R133L, and the C-terminal immunoglobulin-like globular domain for mutation R482W [1]. However at the clinical level they are all responsible for a lipodystrophy syndrome with metabolic alterations and precocious atherosclerosis, either typical for mutation R482W (known as FPLD2), or associated with progeroid dysmorphic signs in patients with $\mathrm{D} 47 \mathrm{Y}$ and R133L mutations [10, 12, 15, 37, 45, 46]. Although the precise structural alterations resulting from D47Y and R133L mutations have not been deciphered, LMNA R482W mutation, which affects a solvent-exposed site at the surface of the protein [47], is known to alter the binding of lamin A to several biological partners [48-50].

In addition, substituted amino acids are replaced by a hydrophobic residue, resulting in a loss of charge in the three cases. Farnesylated prelamin A has to penetrate twice profoundly in the buried catalytic site of ZMPSTE24 for its complete proteolytic processing [51]. This probably imposes important structural constraints, explaining that the mutations located in different domains of the protein could similarly alter the recognition of farnesylated prelamin A by ZMPSTE24, resulting on its altered maturation.

PI combinations, LPV/r, ATV/r and DRV/r, were used at clinical Cmax concentrations. All, except DRV/r, were previously shown to directly inhibit ZMPSTE24 activity and induce cellular accumulation of prelamin $A$, although the mechanisms were not precisely described [21-23, 52]. Although the PI combinations LPV/r, ATV/r, but not DRV/r, exerted a direct toxicity on VSMCs, their impact differed, LPV/r being more deleterious than ATV/r, and DRV/r having minor consequences. Our results are in accordance with clinical data that documented that, among currently used PIs, LPV/r has been associated with a greater risk of cardiovascular disease [20, 35, 36]. ATV has not been associated with an increased risk of myocardial infarction in the D:A:D study [53], but, boosted with ritonavir (ATV/r), it exerted an atherogenic lipid profile [54]. No data being available on a potential cardiovascular risk exerted by DRV, DRV-based therapies are considered as safe and well-tolerated at the metabolic level [55-57].

We reveal here the major role of defective ZMPSTE24 expression in the dysfunction of LMNAmutated or PI-treated VSMCs. This role was supported by several observations: 1- ZMPSTE24 silencing in native VSMCs could rapidly mimic all the effects produced by LMNA mutations or PI 
treatment, including oxidative stress, inflammation, senescence and transdifferentiation/calcification. 2- Pravastatin and FTI-277 that impaired prelamin A farnesylation and thus reduced LMNAmutation- or LPV/r-induced toxicity of prelamin A, also prevented ZMPSTE24 downregulation and VSMC dysfunctions. In agreement, farnesyl synthesis or transferase inhibitors could improve vascular stiffness in patients with HGPS $[58,59]$. Besides the inhibition of HMG-CoA reductase in the mevalonate pathway, pravastatin also exerts antioxidant and anti-inflammatory effects [60], suggesting that ROS generated by the accumulation of the toxic form of prelamin A play a role in ZMPSTE24 downregulation. This is supported by the beneficial effect of the antioxidant NAC on ZMPSTE24 protein level and PI-induced VSMC dysfunctions. 3- Finally, we observed that miRNA141-3p, a negative regulator of ZMPSTE24 expression involved in human cellular aging [40], could also participate in ZMPSTE24 downregulation.

Thus, ZMPSTE24 could be negatively modulated via several pathways that probably concurred to a global dysfunction of VSMCs. Continuous accumulation of farnesylated prelamin A could lead to enhanced toxicity, which, through oxidative stress and inflammation, could reinforce the inhibition/downregulation of ZMPSTE24.

We also showed that the calcification process was not a major initiating factor of premature senescence in VSMCs. Indeed, LPV/r-induced senescence, including dysregulation of ZMPSTE24 and prelamin A, was not modified when osteogenesis/calcification was blocked by either Runx2 silencing, or a co-treatment with etidronate. This suggests that the senescence features resulting from PI treatment preceded and controlled the calcification process.

Our study has some limitations: 1- We could not directly address the association between prelamin A accumulation, ZMPSTE24 depletion and calcification in arterial samples from patients 2- Our results do not exclude that metabolic disorders or lipodystrophy could also contribute to the risk of atherosclerosis observed in patients bearing LMNA mutations [15] or under PI treatment [20]. 3- In contrast with our studies, Perrin et al. [61] did not detect any prelamin A in PBMCs samples from HIV-infected patients under PI therapy. In view of the present results, it would be important to evaluate ZMPSTE24 level in their samples.

In conclusion, we propose that arterial calcified atheromatous plaques prematurely observed in patients with LMNA mutations, and in HIV-infected patients treated with some PIs, share common pathophysiological mechanisms initiated by farnesylated prelamin A persistent accumulation and ZMPSTE24 downregulation, and leading to premature cellular senescence and calcification of vascular cells. Our results suggest that statins or etidronate may prevent vascular calcifications in 
these patients, and that therapies aiming to increase ZMPSTE24 should provide promising options. Further investigations are required regarding the role of ZMPSTE24 in physiological vascular ageing.

\section{Funding}

This work was supported by Institut National de la Santé Et de la Recherche Médicale (INSERM), Université Pierre et Marie Curie (UPMC) and Agence Nationale de Recherches sur le Sida et les hépatites virales (ANRS).

$P$. Afonso is a recipient of a fellowship from the Ministère de l'Enseignement Supérieur et de la Recherche.

\section{Acknowledgments}

The authors thank Thomas Aranias and Yoann Schumacher who participated in the initiation of this study.

\section{Disclosures}

None 


\section{Legends}

Figure 1: Protein expression of prelamin A and ZMPSTE24 in fibroblasts from patients with LMNA mutations, in PBMCs from HIV-infected patients receiving antiretroviral treatments, and in LMNA-mutated or PI-treated VSCMs. Expression of prelamin A, ZMPSTE24 and $\beta$-actin or a-tubulin (loading controls) was evaluated. (A) Fibroblasts from 4 controls and 8 patients with heterozygous LMNA mutations (1 with D47Y, 1 with R133L, and 6 with R482W mutations) (left panel) and PBMCs from 5 HIV-infected patients, during their long-term ART including or not PIs, and after 4 months of maraviroc/raltegravir (M/R) PI-sparing treatment, as indicated (right panel). (B) VSMCs transfected with Flag-tagged wild-type (WT), D47Y-, R133L- or R482W-mutated prelamin A cDNA or with empty pSVK3 (void) vectors, or submitted to transfection reagent only (control) and studied at day 7 (left panel), and VSMCs cultured or not for 21 days with the indicated PIs or the solvent only (DMSO) (right panel). Relative quantifications are expressed as arbitrary units $(\mathrm{AU})$ (mean $\pm \mathrm{SEM}) .{ }^{*} \mathrm{p}<0.05$ versus control patient fibroblasts or versus WT LMNAtransfected cells or versus DMSO-incubated cells.

Figure 2: VSMCs overexpressing mutant $L M N A$ or treated with PIs show increased oxidative stress, inflammation and premature senescence. VSMCs were transfected with Flag-tagged wild-type (WT), D47Y-, R133L- or R482W-mutated prelamin A cDNA or with empty pSVK3 (void) vectors, or submitted to transfection reagent only (control) and studied at day 7 , or were cultured or not for 21 days with the indicated PIs or the solvent only (DMSO). (A) Oxidative stress was evaluated by NBT reduction and $\mathrm{CM}-\mathrm{H}_{2}$ DCFDA oxidation; (B) inflammation by NF-KB activation and IL-13, IL-33, IL-6 and MCP-1 expression and (C) senescence by SA- $\beta$-galactosidase activity (X-gal staining $\mathrm{pH} 6 / \mathrm{pH} 4$ quantification and phase contrast microscopy for $\mathrm{pH} 6)$, by protein expression of the markers of senescence p16 ${ }^{\text {INK4 }}$, p2 $1^{\text {WAF }}, p$-p53/p53 and by cells staining with DAPI (blue), antiprelamin A (green) and anti- $\mathrm{H} 2 \mathrm{AX}$ (red) antibodies (visualized by immunofluorescence microscopy). Representative blots (performed in triplicate) are shown. $\alpha$-tubulin was used as a loading control. Results are means \pm SEM. * $p<0.05$ versus WT LMNA-transfected cells or DMSOincubated cells. Scale bar represent $10 \mu \mathrm{m}$.

Figure 3: LMNA mutations and PIs induce osteogenic transdifferentiation of VSMCs. VSMCs were transfected with flag-tagged wild-type (WT), D47Y-, R133L- or R482W-mutated prelamin A cDNA, or with empty pSVK3 (void) vectors or were cultured for 21 days with the indicated PIs. (A) Protein expression of osteocalcin and Runx2, (B) ALP activity, (C) Alizarin red staining quantification and phase contrast microscopy of stained cells and (D) $\alpha$-SM-actin protein expression and immunofluorescence microscopy of cells labelled with prelamin A (red) and a-SM-actin (green). Representative blots (performed in triplicate) are shown. $\alpha$-tubulin was used as a loading control. 
Scale bars represent $10 \mu \mathrm{m}$. Results are expressed as means \pm SEM and normalized to the protein content. * $p<0.05$ versus WT LMNA-transfected cells or versus DMSO-incubated cells.

Figure 4: Role of ZMPSTE24 in VSMC dysfunctions. Control VSMCs transfected with ZMPSTE24 siRNA were analyzed for the markers of (A) oxidative stress and inflammation, (B) senescence, and (C) osteogenesis/calcification. (D) miRNA-141-3p was quantified in LMNA-mutant and LPV/r-treated cells. Representative blots (performed in triplicate) are shown. $\alpha$-tubulin was used as a loading control. Results are expressed as means \pm SEM and normalized to the protein content. * $p<0.05$ versus DMSO-incubated or scramble- or WT LMNA-transfected cells.

\section{Figure 5: Beneficial effect of pravastatin on LMNA-transfected and PI-induced VSMC} dysfunctions and of FTI-277 and of NAC on PI-induced VSMC dysfunctions. VSMCs were (A, upper panel) transfected with Flag-tagged wild-type (WT), D47Y-, R133L- or R482W-mutated prelamin A cDNA, or with empty pSVK3 (void) vectors and studied at day 7, or (A, bottom panel-BC) cultured for 21 days with LPV/r or with the solvent only (DMSO). (A) Pravastatin (prava, 25 $\mu \mathrm{mol} / \mathrm{L}$, all along the transfection or the PI treatment) or (B) FTI-277 (20 $\mu \mathrm{mol} / \mathrm{L}$, for the last 3 days of LPV/r treatment) or (C) NAC (1 mmol/L, for the last 4 days of LPV/r treatment) were added. The markers of oxidative stress, inflammation and osteogenesis/calcification were evaluated.

Representative blots (performed in triplicate) are shown. $\alpha$-tubulin was used as a loading control. Results are expressed as means \pm SEM and normalized to the protein content. ${ }^{*} \mathrm{p}<0.05$ versus WT LMNA-transfected cells or DMSO-incubated cells. $\S p<0.05$ versus LPV/r-only incubated cells or versus respective mutant without prava. \# $\mathrm{p}<0.05$ versus WT LMNA-transfected and pravaincubated cells or versus DMSO- and prava- or FTI-277-incubated cells. 


\section{References}

[1] Mattout A, Dechat T, Adam SA, Goldman RD, Gruenbaum Y. Nuclear lamins, diseases and aging. Curr Opin Cell Biol 2006;18:335-41.

[2] Fong LG, Ng JK, Meta M, Cote N, Yang SH, Stewart CL, et al. Heterozygosity for Lmna deficiency eliminates the progeria-like phenotypes in Zmpste24-deficient mice. Proc Natl Acad Sci U S A 2004;101:18111-6.

[3] Glynn MW, Glover TW. Incomplete processing of mutant lamin A in Hutchinson-Gilford progeria leads to nuclear abnormalities, which are reversed by farnesyltransferase inhibition. Hum Mol Genet 2005;14:2959-69.

[4] Fong LG, Frost D, Meta M, Qiao X, Yang SH, Coffinier C, et al. A protein farnesyltransferase inhibitor ameliorates disease in a mouse model of progeria. Science 2006;311:1621-3.

[5] Eriksson M, Brown WT, Gordon LB, Glynn MW, Singer J, Scott L, et al. Recurrent de novo point mutations in lamin A cause Hutchinson-Gilford progeria syndrome. Nature 2003;423:293-8.

[6] Cadinanos J, Varela I, Lopez-Otin C, Freije JM. From immature lamin to premature aging: molecular pathways and therapeutic opportunities. Cell Cycle 2005;4:1732-5.

[7] De Sandre-Giovannoli A, Bernard R, Cau P, Navarro C, Amiel J, Boccaccio I, et al. Lamin a truncation in Hutchinson-Gilford progeria. Science 2003;300:2055.

[8] Varela I, Cadinanos J, Pendas AM, Gutierrez-Fernandez A, Folgueras AR, Sanchez LM, et al. Accelerated ageing in mice deficient in Zmpste24 protease is linked to p53 signalling activation. Nature 2005;437:564-8.

[9] Barrowman J, Michaelis S. ZMPSTE24, an integral membrane zinc metalloprotease with a connection to progeroid disorders. Biol Chem 2009;390:761-73.

[10] Caron M, Auclair M, Donadille B, Bereziat V, Guerci B, Laville M, et al. Human lipodystrophies linked to mutations in A-type lamins and to HIV protease inhibitor therapy are both associated with prelamin A accumulation, oxidative stress and premature cellular senescence. Cell Death Differ 2007;14:1759-67.

[11] Capanni C, Mattioli E, Columbaro M, Lucarelli E, Parnaik VK, Novelli G, et al. Altered pre-lamin A processing is a common mechanism leading to lipodystrophy. Hum Mol Genet 2005;14:1489-502.

[12] Caux F, Dubosclard E, Lascols O, Buendia B, Chazouilleres O, Cohen A, et al. A new clinical condition linked to a novel mutation in lamins $A$ and $C$ with generalized lipoatrophy, insulin-resistant diabetes, disseminated leukomelanodermic papules, liver steatosis, and cardiomyopathy. J Clin Endocrinol Metab 2003;88:1006-13.

[13] Capell BC, Collins FS, Nabel EG. Mechanisms of cardiovascular disease in accelerated aging syndromes. Circ Res 2007;101:13-26.

[14] Olive M, Harten I, Mitchell R, Beers JK, Djabali K, Cao K, et al. Cardiovascular pathology in Hutchinson-Gilford progeria: correlation with the vascular pathology of aging. Arteriosclerosis, thrombosis, and vascular biology 2010;30:2301-9. 
[15] Bidault G, Garcia M, Vantyghem MC, Ducluzeau PH, Morichon R, Thiyagarajah K, et al. Lipodystrophy-linked LMNA p.R482W mutation induces clinical early atherosclerosis and in vitro endothelial dysfunction. Arterioscler Thromb Vasc Biol 2013;33:2162-71.

[16] Ragnauth CD, Warren DT, Liu Y, McNair R, Tajsic T, Figg N, et al. Prelamin A acts to accelerate smooth muscle cell senescence and is a novel biomarker of human vascular aging. Circulation 2010;121:2200-10.

[17] Liu Y, Drozdov I, Shroff R, Beltran LE, Shanahan CM. Prelamin a accelerates vascular calcification via activation of the DNA damage response and senescence-associated secretory phenotype in vascular smooth muscle cells. Circ Res 2013;112:e99-e109.

[18] Micheletti RG, Fishbein GA, Fishbein MC, Singer EJ, Weiss RE, Jeffries RA, et al. Coronary atherosclerotic lesions in human immunodeficiency virus-infected patients: a histopathologic study. Cardiovascular pathology : the official journal of the Society for Cardiovascular Pathology 2009;18:28-36.

[19] Guaraldi G, Zona S, Orlando G, Carli F, Ligabue G, Fiocchi F, et al. Human immunodeficiency virus infection is associated with accelerated atherosclerosis. The Journal of antimicrobial chemotherapy 2011;66:1857-60.

[20] Boccara F, Lang S, Meuleman C, Ederhy S, Mary-Krause M, Costagliola D, et al. HIV and coronary heart disease: time for a better understanding. J Am Coll Cardiol 2013;61:511-23.

[21] Caron M, Auclair M, Vigouroux C, Glorian M, Forest C, Capeau J. The HIV protease inhibitor indinavir impairs sterol regulatory element-binding protein-1 intranuclear localization, inhibits preadipocyte differentiation, and induces insulin resistance. Diabetes 2001;50:1378-88.

[22] Coffinier C, Hudon SE, Farber EA, Chang SY, Hrycyna CA, Young SG, et al. HIV protease inhibitors block the zinc metalloproteinase ZMPSTE24 and lead to an accumulation of prelamin A in cells. Proc Natl Acad Sci U S A 2007;104:13432-7.

[23] Hudon SE, Coffinier C, Michaelis S, Fong LG, Young SG, Hrycyna CA. HIV-protease inhibitors block the enzymatic activity of purified Ste24p. Biochem Biophys Res Commun 2008;374:365-8.

[24] Lefevre C, Auclair M, Boccara F, Bastard JP, Capeau J, Vigouroux C, et al. Premature senescence of vascular cells is induced by HIV protease inhibitors: implication of prelamin $A$ and reversion by statin. Arterioscler Thromb Vasc Biol 2010;30:2611-20.

[25] Bonello-Palot N, Simoncini S, Robert S, Bourgeois P, Sabatier F, Levy N, et al. Prelamin A accumulation in endothelial cells induces premature senescence and functional impairment. Atherosclerosis 2014;237:45-52.

[26] Auclair M, Afonso P, Capel E, Caron-Debarle M, Capeau J. Impact of darunavir, atazanavir and lopinavir boosted with ritonavir on cultured human endothelial cells: beneficial effect of pravastatin. Antivir Ther 2014.

[27] Byon CH, Javed A, Dai Q, Kappes JC, Clemens TL, Darley-Usmar VM, et al. Oxidative stress induces vascular calcification through modulation of the osteogenic transcription factor Runx 2 by AKT signaling. J Biol Chem 2008;283:15319-27.

[28] Kalra SS, Shanahan CM. Vascular calcification and hypertension: cause and effect. Ann Med 2012;44 Suppl 1:S85-92. 
[29] Demer LL, Tintut Y. Inflammatory, metabolic, and genetic mechanisms of vascular calcification. Arterioscler Thromb Vasc Biol 2014;34:715-23.

[30] Burton DG, Giles PJ, Sheerin AN, Smith SK, Lawton JJ, Ostler EL, et al. Microarray analysis of senescent vascular smooth muscle cells: A link to atherosclerosis and vascular calcification. Exp Gerontol 2009;44:659-65.

[31] Burton DG, Matsubara H, Ikeda K. Pathophysiology of vascular calcification: Pivotal role of cellular senescence in vascular smooth muscle cells. Exp Gerontol 2010;45:819-24.

[32] Kramer CK, Zinman B, Gross JL, Canani LH, Rodrigues TC, Azevedo MJ, et al. Coronary artery calcium score prediction of all cause mortality and cardiovascular events in people with type 2 diabetes: systematic review and meta-analysis. BMJ 2013;346:f1654.

[33] Guaraldi G, Zona S, Alexopoulos N, Orlando G, Carli F, Ligabue G, et al. Coronary aging in HIV-infected patients. Clin Infect Dis 2009;49:1756-62.

[34] Post WS, Budoff M, Kingsley L, Palella FJ, Jr., Witt MD, Li X, et al. Associations between HIV infection and subclinical coronary atherosclerosis. Ann Intern Med 2014;160:458-67.

[35] Lang S, Mary-Krause M, Cotte L, Gilquin J, Partisani M, Simon A, et al. Impact of individual antiretroviral drugs on the risk of myocardial infarction in human immunodeficiency virus-infected patients: a case-control study nested within the French Hospital Database on HIV ANRS cohort CO4. Arch Intern Med 2010;170:1228-38.

[36] Worm SW, Sabin C, Weber R, Reiss P, El-Sadr W, Dabis F, et al. Risk of myocardial infarction in patients with HIV infection exposed to specific individual antiretroviral drugs from the 3 major drug classes: the data collection on adverse events of anti-HIV drugs (D:A:D) study. J Infect Dis 2010;201:318-30.

[37] Decaudain A, Vantyghem MC, Guerci B, Hecart AC, Auclair M, Reznik Y, et al. New metabolic phenotypes in laminopathies: LMNA mutations in patients with severe metabolic syndrome. J Clin Endocrinol Metab 2007;92:4835-44.

[38] Katlama C, Assoumou L, Valantin MA, Soulie C, Duvivier C, Chablais L, et al. Maraviroc plus raltegravir failed to maintain virological suppression in HIV-infected patients with lipohypertrophy: results from the ROCnRAL ANRS 157 study. J Antimicrob Chemother 2014;69:1648-52.

[39] Giachelli CM. Vascular calcification mechanisms. J Am Soc Nephrol 2004;15:2959-64.

[40] Yu KR, Lee S, Jung JW, Hong IS, Kim HS, Seo Y, et al. MicroRNA-141-3p plays a role in human mesenchymal stem cell aging by directly targeting ZMPSTE24. J Cell Sci 2013;126:542231.

[41] Olsen PH, Ambros $\mathrm{V}$. The lin-4 regulatory RNA controls developmental timing in Caenorhabditis elegans by blocking LIN-14 protein synthesis after the initiation of translation. Dev Biol 1999;216:671-80.

[42] Russell RG. Bisphosphonates: the first 40 years. Bone 2011;49:2-19.

[43] Caron M, Vigouroux C, Bastard J-P, Capeau J. Adipocyte dysfunction in response to antiretroviral therapy : clinical, tissue and in-vitro studies. Curr Opin HIV AIDS 2007;2:268-73. 
[44] Bereziat V, Cervera P, Le Dour C, Verpont MC, Dumont S, Vantyghem MC, et al. LMNA mutations induce a non-inflammatory fibrosis and a brown fat-like dystrophy of enlarged cervical adipose tissue. Am J Pathol 2011;179:2443-53.

[45] Chen L, Lee L, Kudlow BA, Dos Santos HG, Sletvold O, Shafeghati Y, et al. LMNA mutations in atypical Werner's syndrome. Lancet 2003;362:440-5.

[46] Todorovic S, Milenkovic T, K. M, Zdravkovic D, Stajic N, Vukovic R. Atypical progeroid syndrome - case report. Horm Res 2012;78 164.

[47] Krimm I, Ostlund C, Gilquin B, Couprie J, Hossenlopp P, Mornon JP, et al. The Ig-like structure of the C-terminal domain of lamin $\mathrm{A} / \mathrm{C}$, mutated in muscular dystrophies, cardiomyopathy, and partial lipodystrophy. Structure 2002;10:811-23.

[48] Stierle V, Couprie J, Ostlund C, Krimm I, Zinn-Justin S, Hossenlopp P, et al. The carboxylterminal region common to lamins $\mathrm{A}$ and $\mathrm{C}$ contains a DNA binding domain. Biochemistry 2003;42:4819-28.

[49] Oldenburg AR, Delbarre E, Thiede B, Vigouroux C, Collas P. Deregulation of Fragile X-related protein 1 by the lipodystrophic lamin A p.R482W mutation elicits a myogenic gene expression program in preadipocytes. Hum Mol Genet 2014;23:1151-62.

[50] Vadrot N, Duband-Goulet I, Cabet E, Attanda W, Barateau A, Vicart P, et al. The p.R482W substitution in A-type lamins deregulates SREBP1 activity in Dunnigan-type familial partial lipodystrophy. Hum Mol Genet 2015;24:2096-109.

[51] Quigley A, Dong YY, Pike AC, Dong L, Shrestha L, Berridge G, et al. The structural basis of ZMPSTE24-dependent laminopathies. Science 2013;339:1604-7.

[52] Coffinier C, Hudon SE, Lee R, Farber EA, Nobumori C, Miner JH, et al. A potent HIV protease inhibitor, darunavir, does not inhibit ZMPSTE24 or lead to an accumulation of farnesyl-prelamin $A$ in cells. J Biol Chem 2008;283:9797-804.

[53] Monforte A, Reiss P, Ryom L, El-Sadr W, Dabis F, De Wit S, et al. Atazanavir is not associated with an increased risk of cardio- or cerebrovascular disease events. AIDS 2013;27:407-15.

[54] Podzamczer D, Andrade-Villanueva J, Clotet B, Taylor S, Rockstroh JK, Reiss P, et al. Lipid profiles for nevirapine vs. atazanavir/ritonavir, both combined with tenofovir disoproxil fumarate and emtricitabine over 48 weeks, in treatment-naive HIV-1-infected patients (the ARTEN study). HIV Med 2011;12:374-82.

[55] Menzaghi B, Ricci E, Carenzi L, Parruti G, Orofino G, Guastavigna M, et al. Safety and durability in a cohort of HIV-1 positive patients treated with once and twice daily darunavir-based therapy (SCOLTA Project). Biomed Pharmacother 2013;67:293-8.

[56] Arathoon E, Schneider S, Baraldi E, Lim PL, Opravil M, Van De Casteele T, et al. Effects of once-daily darunavir/ritonavir versus lopinavir/ritonavir on metabolic parameters in treatment-naive HIV-1-infected patients at week 96: ARTEMIS. Int J STD AIDS 2013;24:12-7.

[57] Orkin C, DeJesus E, Khanlou H, Stoehr A, Supparatpinyo K, Lathouwers E, et al. Final 192week efficacy and safety of once-daily darunavir/ritonavir compared with lopinavir/ritonavir in HIV-1infected treatment-naive patients in the ARTEMIS trial. HIV Med 2013;14:49-59. 
[58] Gordon LB, Kleinman ME, Miller DT, Neuberg DS, Giobbie-Hurder A, Gerhard-Herman M, et al. Clinical trial of a farnesyltransferase inhibitor in children with Hutchinson-Gilford progeria syndrome. Proc Natl Acad Sci U S A 2012;109:16666-71.

[59] Young SG, Yang SH, Davies BS, Jung HJ, Fong LG. Targeting protein prenylation in progeria. Sci Transl Med 2013;5:171ps3.

[60] Bauer AJ, Banek CT, Needham K, Gillham H, Capoccia S, Regal JF, et al. Pravastatin attenuates hypertension, oxidative stress, and angiogenic imbalance in rat model of placental ischemia-induced hypertension. Hypertension 2013;61:1103-10.

[61] Perrin S, Cremer J, Faucher O, Reynes J, Dellamonica P, Micallef J, et al. HIV protease inhibitors do not cause the accumulation of prelamin A in PBMCs from patients receiving first line therapy: the ANRS EP45 "aging" study. PLoS One 2012;7:e53035. 


\section{Supplemental legends}

Figure S1: Evaluation of inflammation, senescence and calcification/transdifferentiation in LMNA-transfected and PI-treated VSMCs. (A) Volume-rendered 3D carotid computed tomography angiography in a 42 year-old patient harboring a p.R133L LMNA heterozygous mutation. Extensive plaque calcifications are shown by arrows at right and left carotid bifurcations. The patient was nonsmoker, physically active with early-screened diabetes and dyslipidemia, which were always wellcontrolled. (B-C-D-E) VSMCs were transfected with Flag-tagged wild-type (WT), D47Y-, R133L- or R482W-mutated prelamin A cDNA, or with empty pSVK3 (void) vectors and studied at day 7 , or were cultured for 21 days with the indicated PIs. Western blot quantifications of (B) Flag in VSMC transfected with LMNA mutated vectors, of markers of (C) inflammation (NF-kB activation) and of (D) senescence $\left(\mathrm{p} 16^{\mathrm{INK} 4}, \mathrm{p} 21^{\mathrm{WAF}}, \mathrm{p}-\mathrm{p} 53 / \mathrm{p} 53\right)$ and of (E) osteogenic transdifferentiation (Runx2 and osteocalcin expression). $\alpha$-tubulin was used as a loading control. Results are expressed as means \pm SEM. * $p<0.05$ versus DMSO-incubated or WT LMNA-transfected cells.

Figure S2: Role of ZMPSTE24 in VSMC dysfunctions. Western Blot of control VSMCs transfected with ZMPSTE24 siRNA were quantified for (A) prelamin A, ZMPSTE24 and NF-kB expression, and for (B) $p 16^{\text {INK4 }}, p 21^{\text {WAF }}, p-p 53 / p 53$, Runx2 and osteocalcin expression. $\alpha$-tubulin was used as a loading control. Results are expressed as means \pm SEM. * $p<0.05$ versus scramble-transfected cells.

Fig. S3: Beneficial effect of pravastatin on LMNA-transfected and PI-induced VSMC dysfunctions. VSMCs were (A) transfected with Flag-tagged wild-type (WT), D47Y-, R133L- or R482W-mutated prelamin A cDNA, or with empty pSVK3 (void) vectors and studied at day 7 , or (B) cultured for 21 days with LPV/r. (A-B) Pravastatin (prava, 25 $\mu \mathrm{mol} / \mathrm{L}$ ) was added all along the transfection or the PI treatment. (A) Prelamin A and ZMPSTE24 expression were quantified (upper panel) and markers of senescence (X-gal staining) and calcification/transdifferentiation (ALP activity and alizarin staining) (bottom panel) were evaluated. (B) Protein expression of HDJ2, markers of senescence (X-gal staining, p16 ${ }^{\text {INK4 }}$ and p21 ${ }^{\mathrm{WAF}}$ expression) and of transdifferentiation/calcification (osteocalcin and Runx2 expression, ALP activity and alizarin staining) were evaluated. $\alpha$-tubulin was used as a loading control. Results are expressed as means \pm SEM. ${ }^{*} \mathrm{p}<0.05$ versus WT LMNAtransfected cells or DMSO-incubated cells. $\S p<0.05$ versus LPV/r-only incubated cells or versus respective mutant without prava. \# $p<0.05$ versus prava- and WT-transfected cells.

Fig. S4: Beneficial effect of FTI-277 on PI-induced VSMC dysfunctions. VSMCs were cultured for 21 days with LPV/r or with the solvent only (DMSO) and FTI-277 (20 $\mu \mathrm{mol} / \mathrm{L})$ was added for the last 3 days. Protein expression of (A) prelamin A and ZMPSTE24 and of (B) p-p65/p65RelA (NF-kB 
activation), (C) markers of senescence (X-gal staining, p16 ${ }^{\mathrm{INK} 4}$ and p2 $1^{\text {WAF }}$ expression) and of (D) calcification/transdifferentiation (ALP activity, Alizarin red staining, and Runx2 and osteocalcin expression) were evaluated. a-tubulin was used as a loading control. Results are expressed as means \pm SEM. * $p<0.05$ versus DMSO-incubated cells. $\S p<0.05$ versus LPV/r-only incubated cells. \# $\mathrm{p}<0.05$ versus $\mathrm{FTI}-277$ - and DMSO-incubated cells.

Fig. S5: Beneficial effect of NAC on PI-induced VSMC dysfunctions. VSMCs were cultured for 21 days with LPV/r or with the solvent only (DMSO) and NAC $(1 \mathrm{mmol} / \mathrm{L})$ was added for the last 4 days. (A) Protein expression of prelamin A and ZMPSTE24 and markers of senescence (X-gal staining, p16 ${ }^{\text {INK4 }}$ and p21 ${ }^{\text {WAF }}$ expression), of (B) inflammation (NF-KB activation) and of (C) calcification/transdifferentiation (Alizarin red staining and Runx2 and osteocalcin expression) were evaluated. $\alpha$-tubulin was used as a loading control. Results are expressed as means \pm SEM. ${ }^{*} p<0.05$ versus DMSO-incubated cells. $\S p<0.05$ versus LPV/r-only incubated cells. $\# p<0.05$ versus NAC- and DMSO-incubated cells.

\section{Figure S6: Impact of Runx2 silencing or etidronate on LPV/r-induced VSMC dysfunctions.} LPV/r-treated VSMCs were transfected with Runx2 siRNA at day 15, or co-cultured with etidronate for 21 days. Impact of Runx2 silencing and etidronate on markers of (A) osteogenesis/calcification (Runx2 and osteocalcin expression, ALP activity and Alizarin red staining), (B) oxidative stress (NBT reduction) and inflammation (NF-KB activation) and (C) protein expression of prelamin $\mathrm{A}$ and ZMPSTE24 and markers of senescence (X-gal staining, p16 ${ }^{\text {INK4 }}$ and p2 $21^{\text {WAF }}$ expression). Representative blots (performed in triplicate) are shown. $\alpha$-tubulin was used as a loading control. Results are means \pm SEM. ns for non significant. * $p<0.05$ versus scramble- or DMSO-incubated cells. § $p<0.05$ versus LPV/r only-incubated cells. \# $p<0.05$ versus DMSO- and etidronate-incubated cells. 
prelamin A

ZMPSTE24
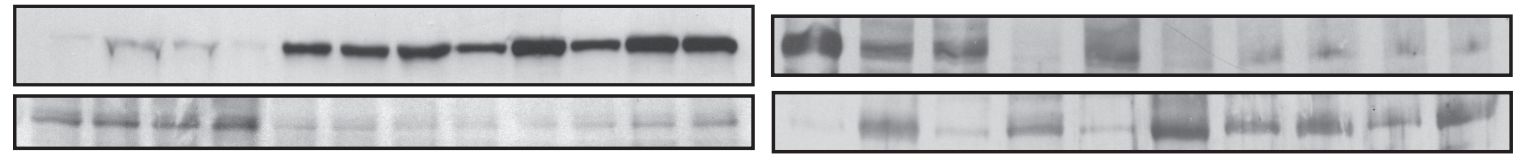

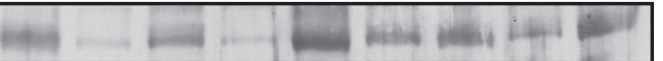

$\beta$-actin

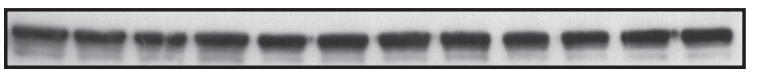

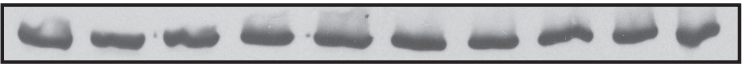

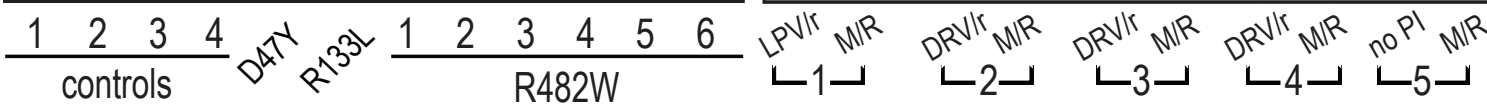

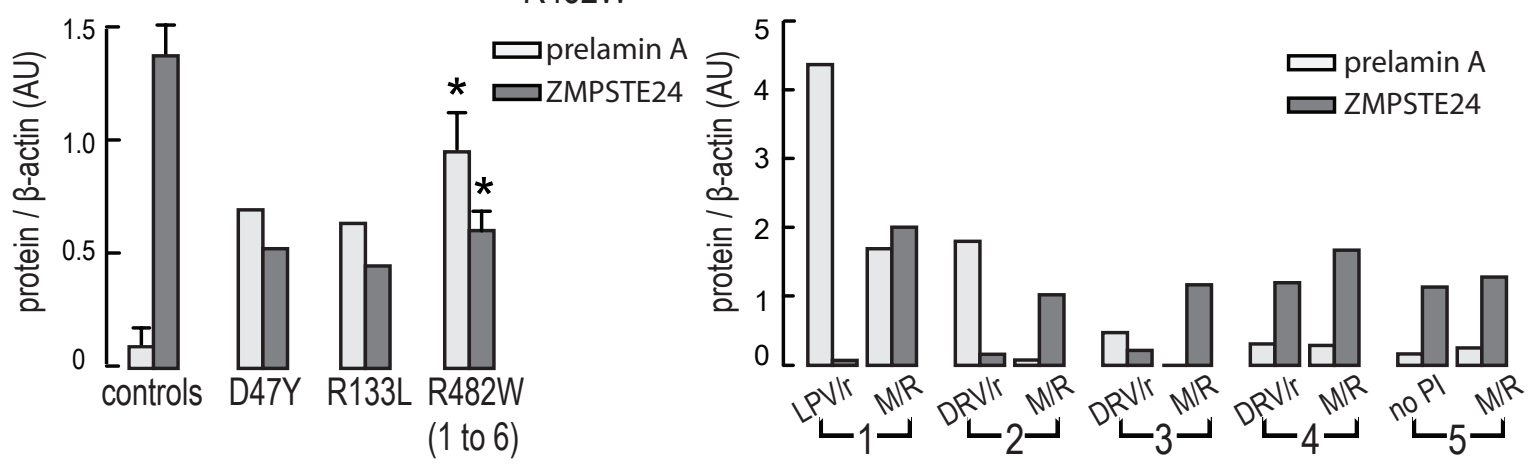

B

\section{LMNA-mutated VSMCs}

flag

prelaminA $\operatorname{lamin} A$ laminC prelaminA ZMPSTE24

a-tubulin
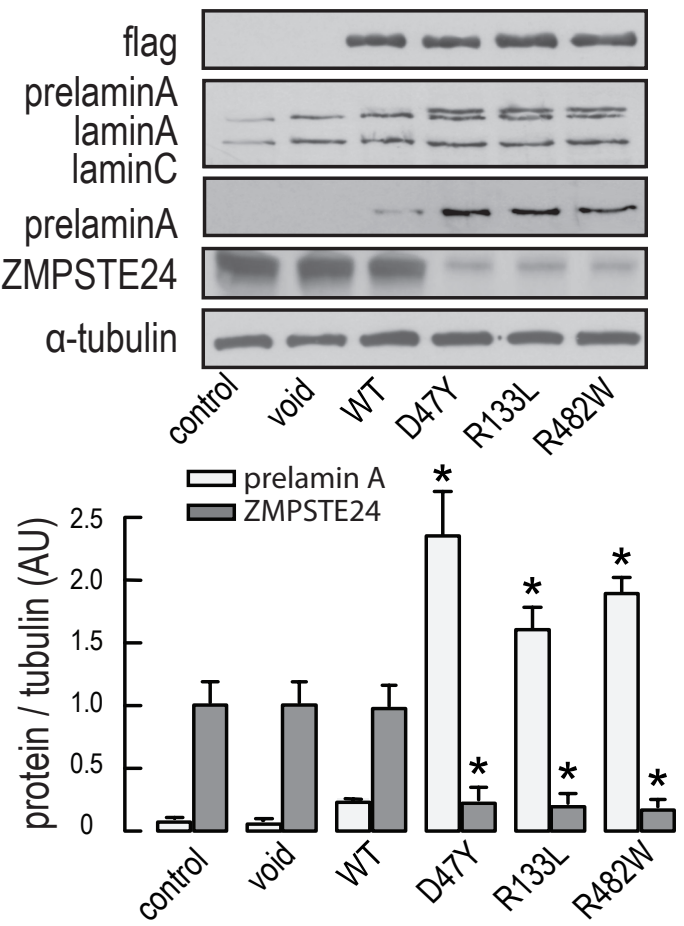

\section{PI-treated VSMCs}

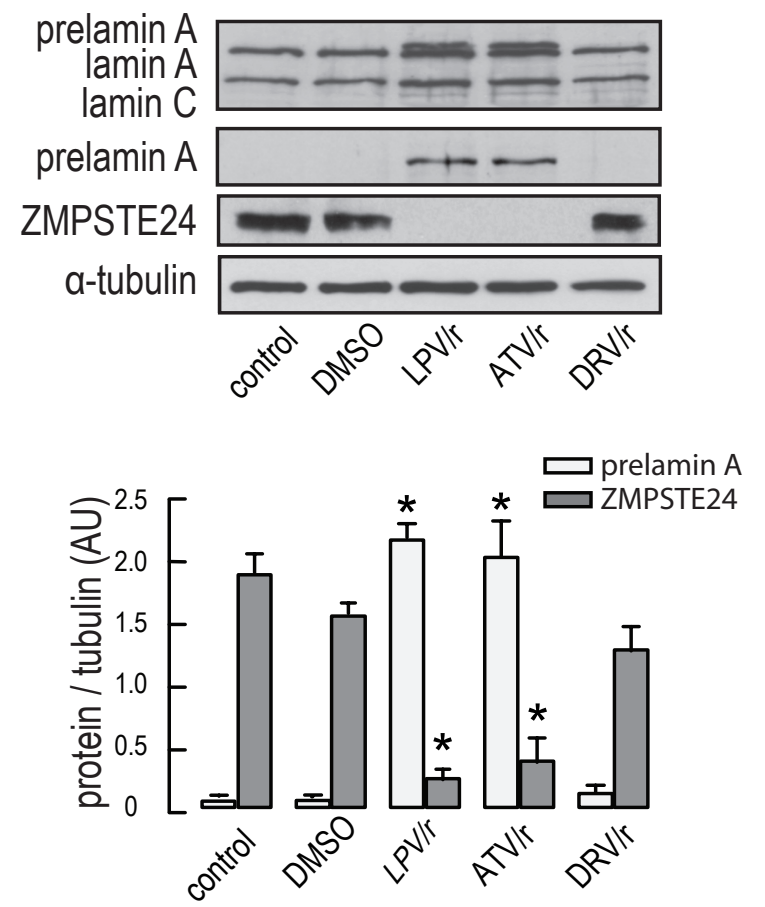


$A$

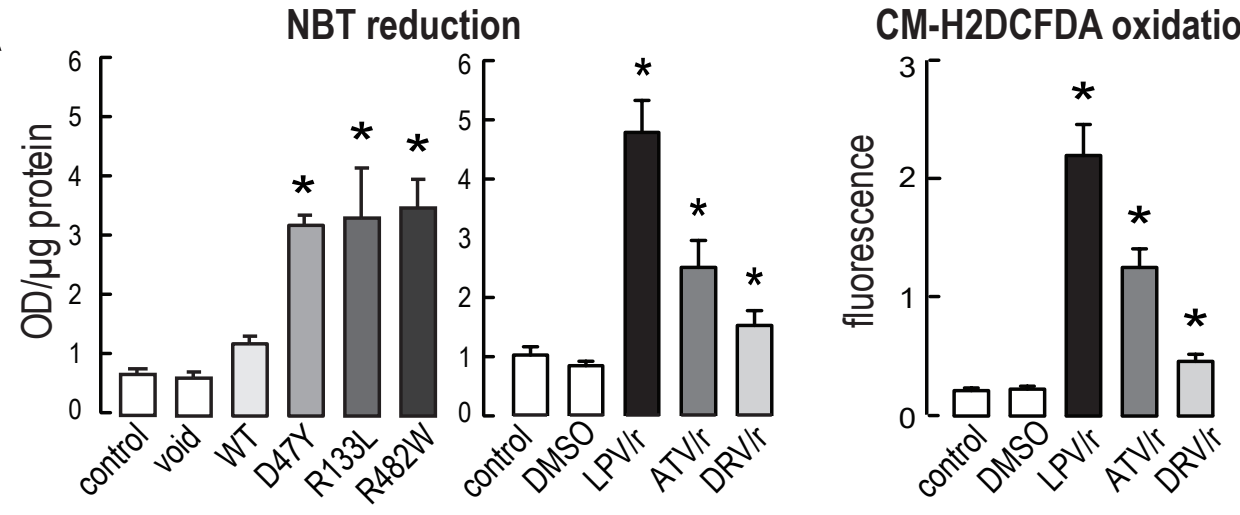

B

\section{NF-kB activation}
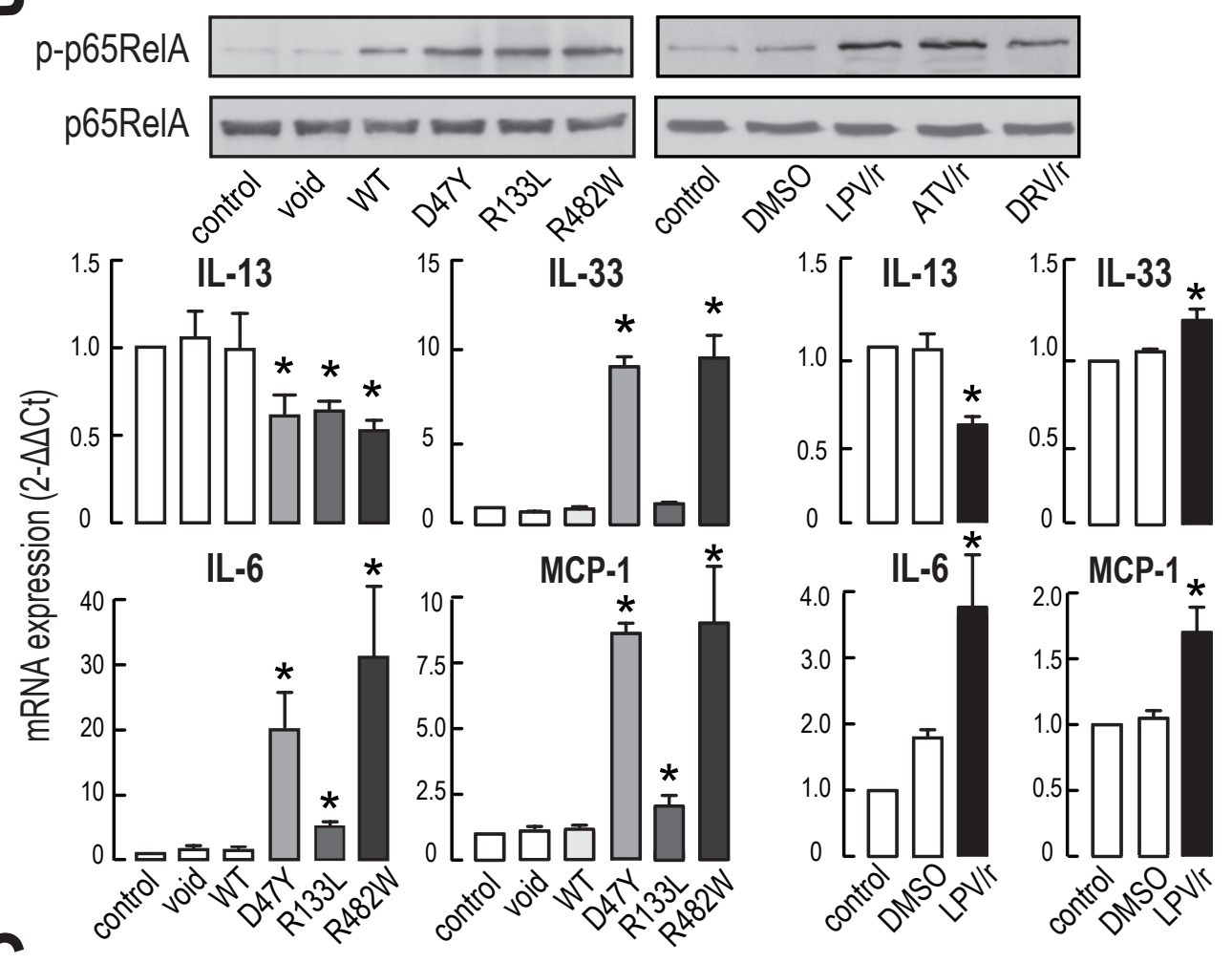

C

senescence
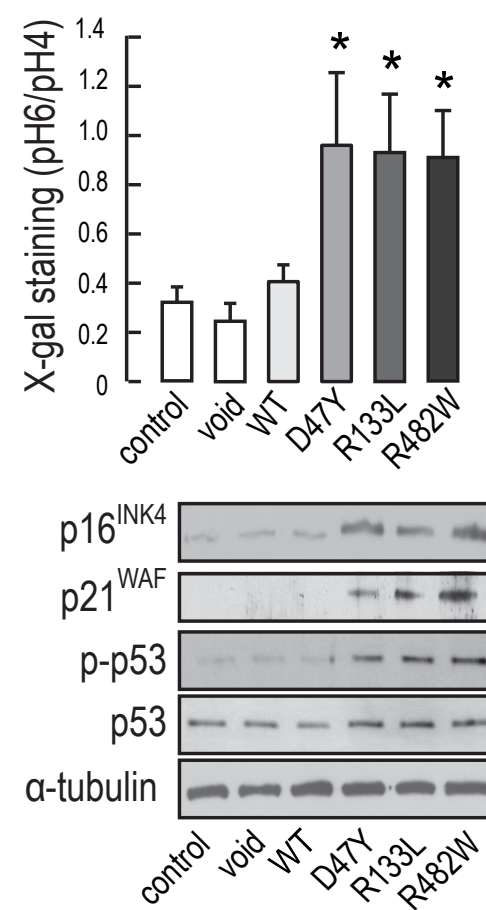
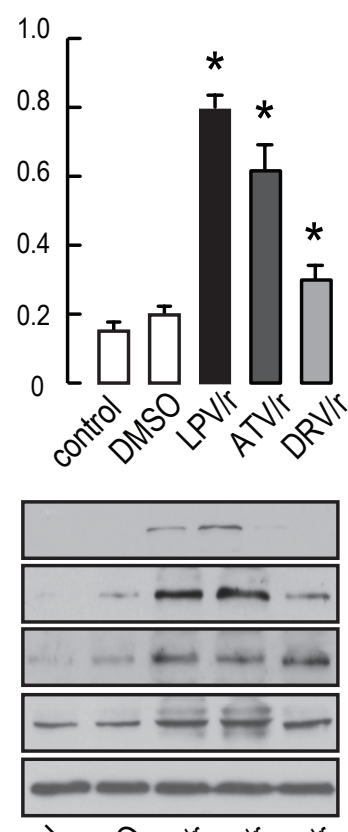

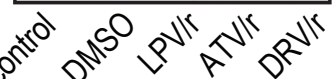

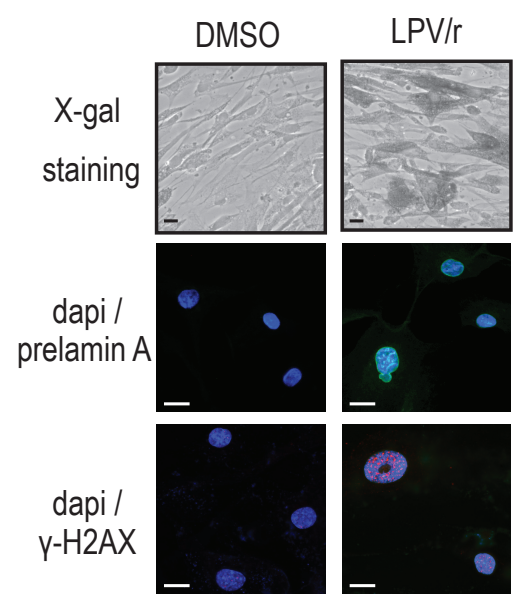




\section{A osteocalcin}
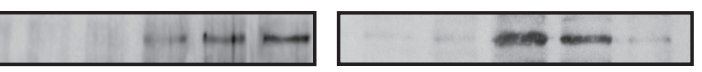

B
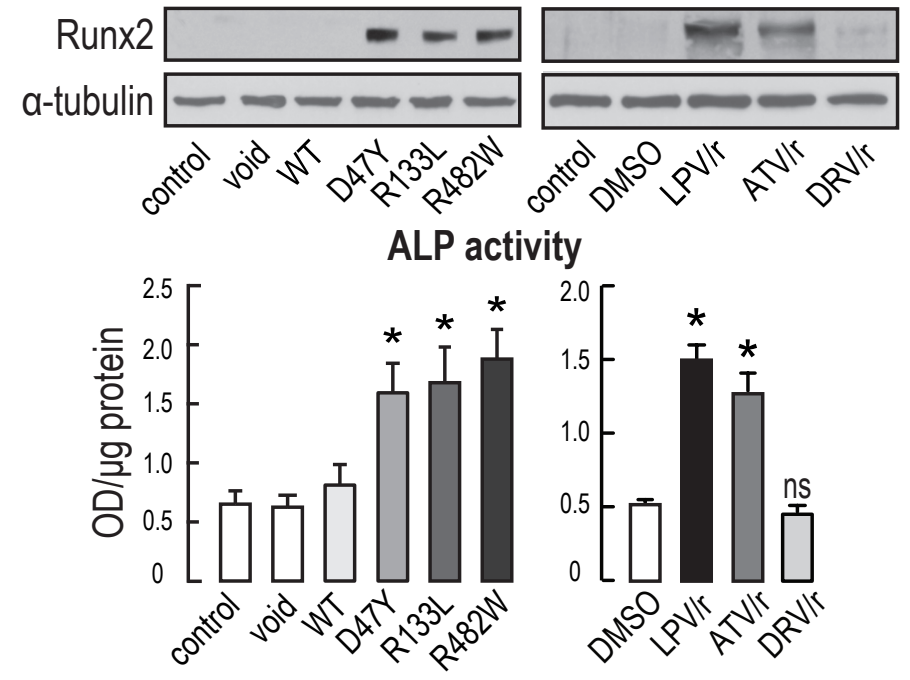

Alizarin red staining
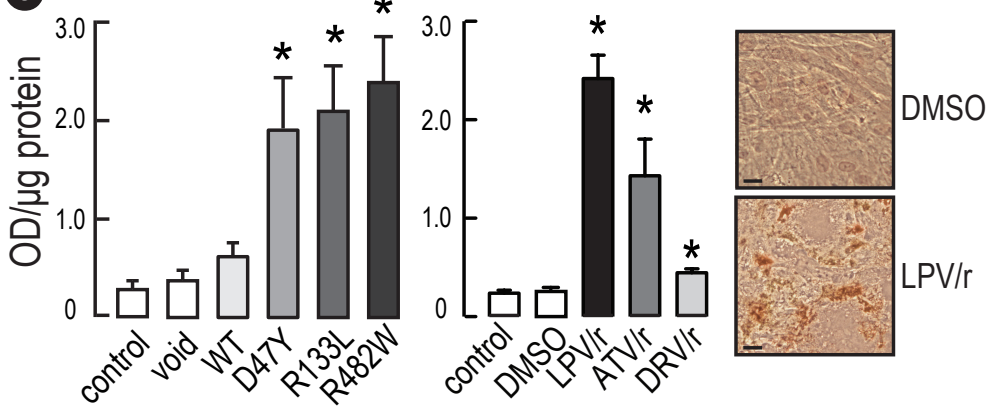

DMSO

\section{a-SM-actin}

a-tubulin
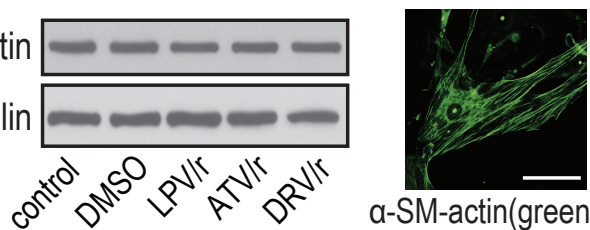

LPV/r

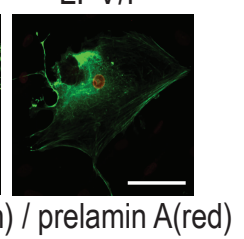

a-SM-actin(green) / prelamin A(red) 
A

prelamin A $\operatorname{lamin} \mathrm{A}$ lamin C prelamin $\mathrm{A}$ ZMPSTE24 a-tubulin

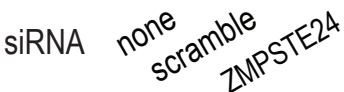

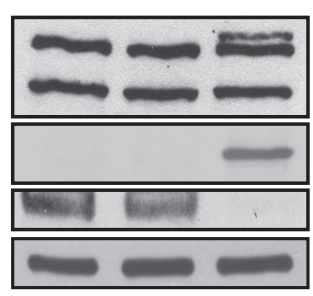

\section{NBT reduction}

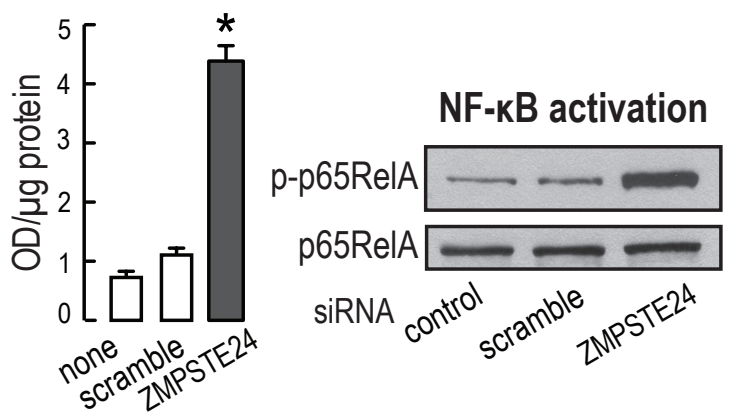

B

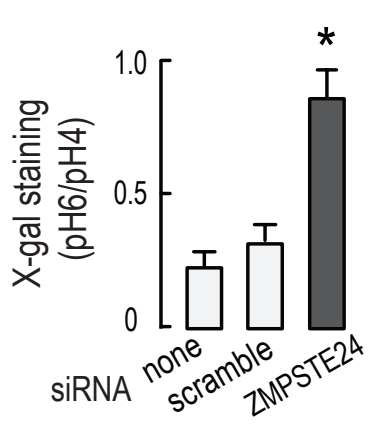

C

osteocalcin

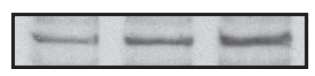

Runx2

a-tubulin siRNA

\section{senescence}

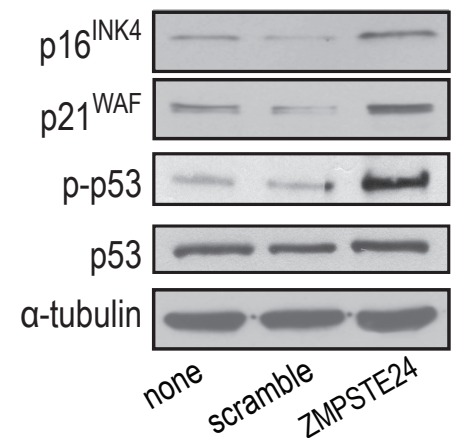

ALP activity Alizarin staining
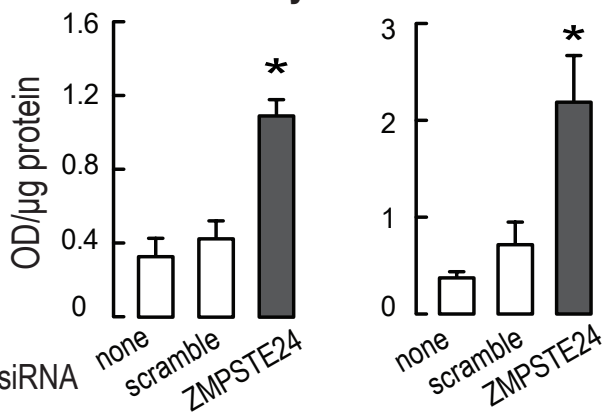

D

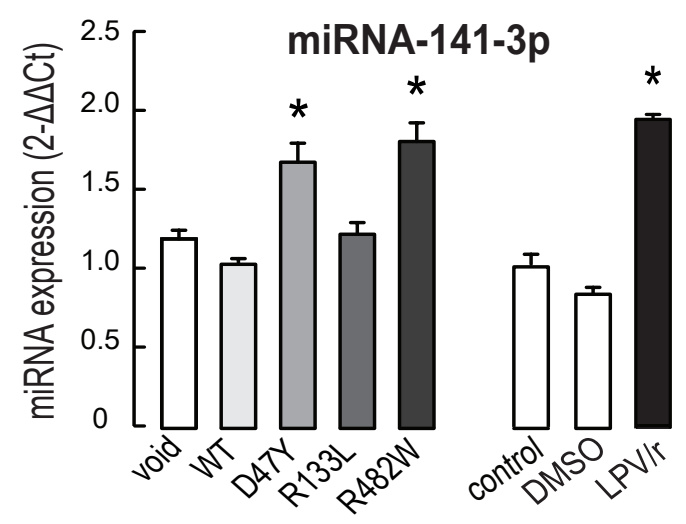




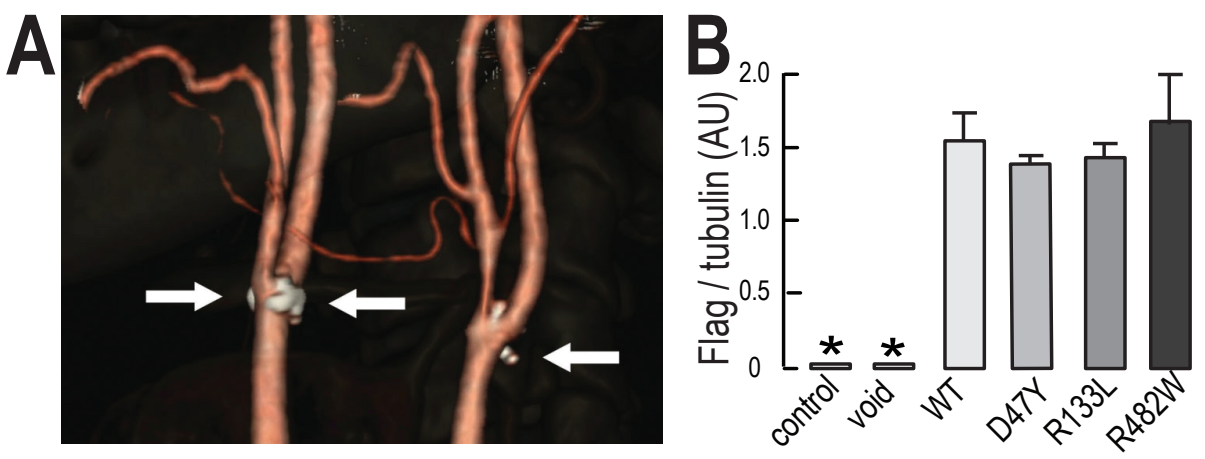

\section{NFkB activation}
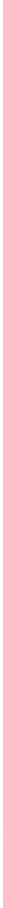

E

\section{osteogenic transdifferentiation}

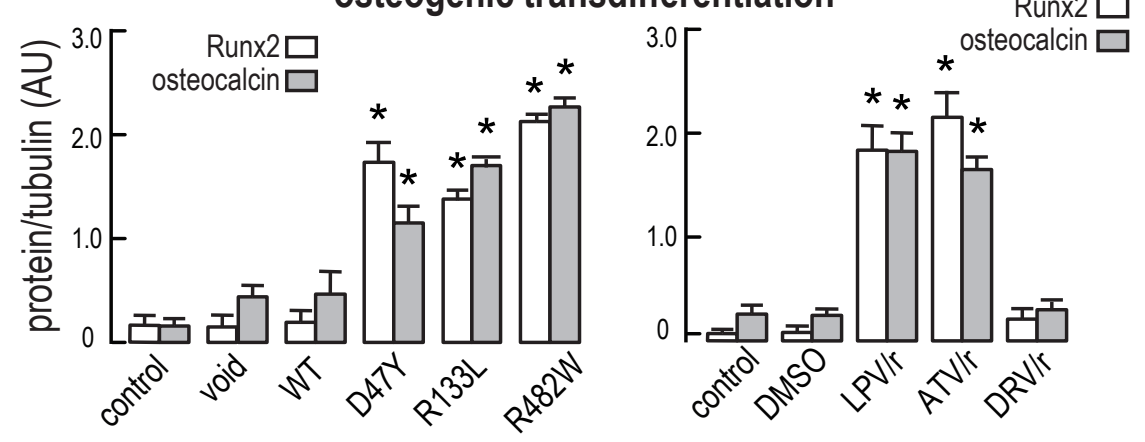


siRNA ZMPSTE24

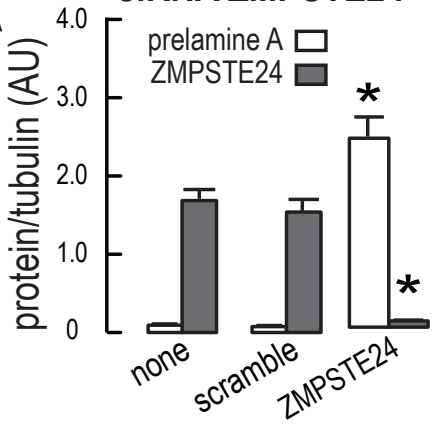

senescence

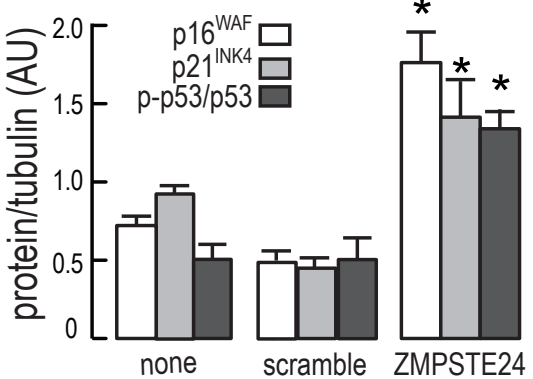

NFkB activation

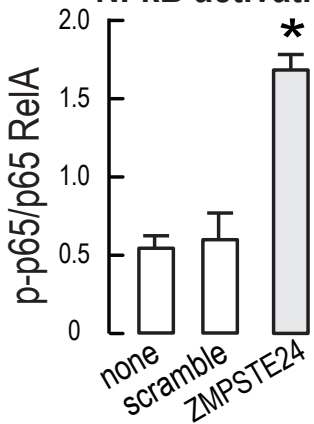

transdifferentiation

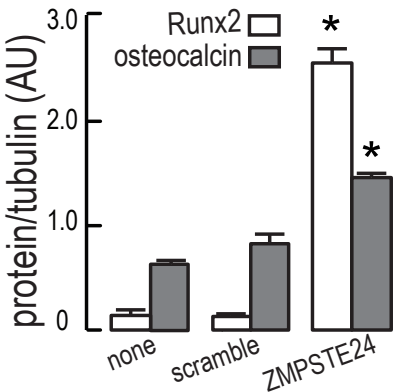




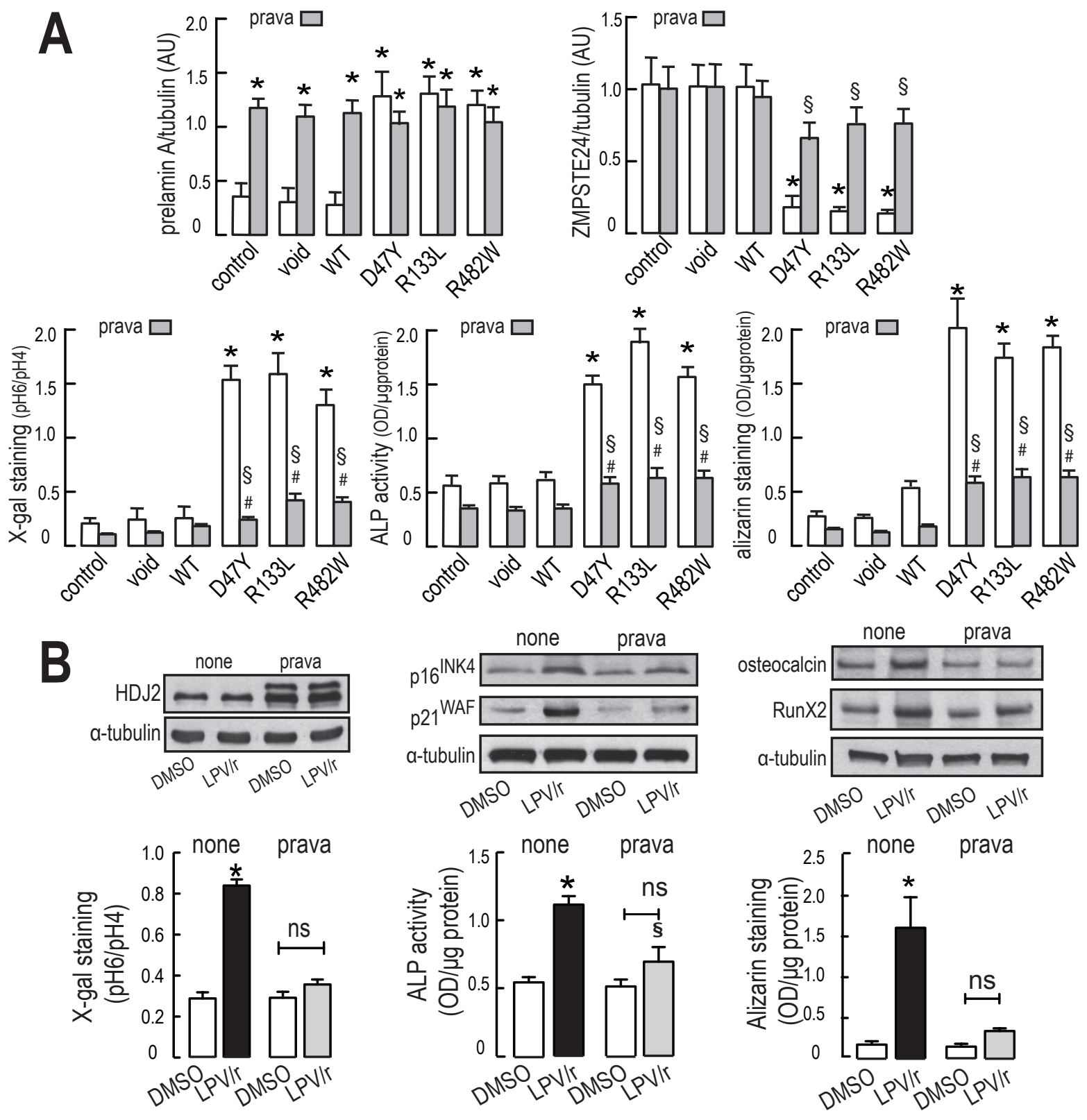


A prelaminA $\square \quad$ ZMPSTE24 $\square$ B $\quad$ p-p65/p65RelA

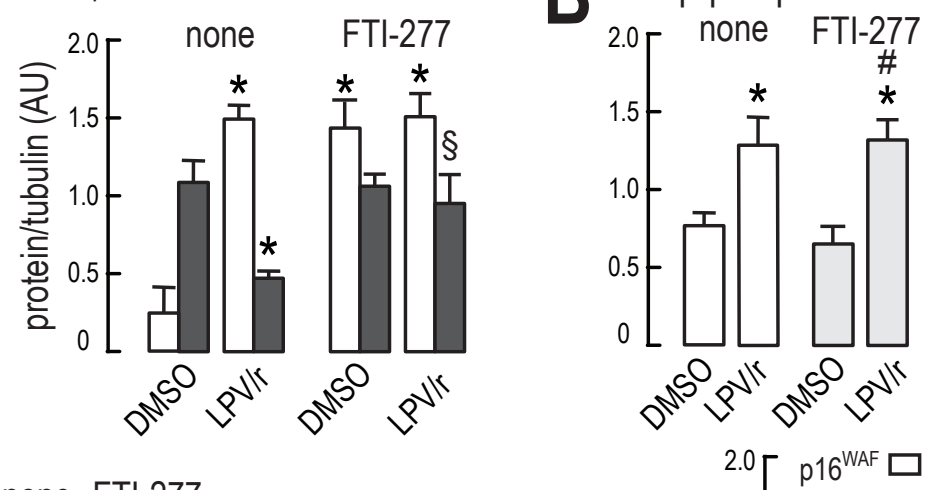

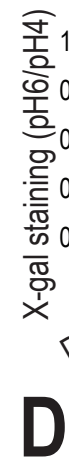
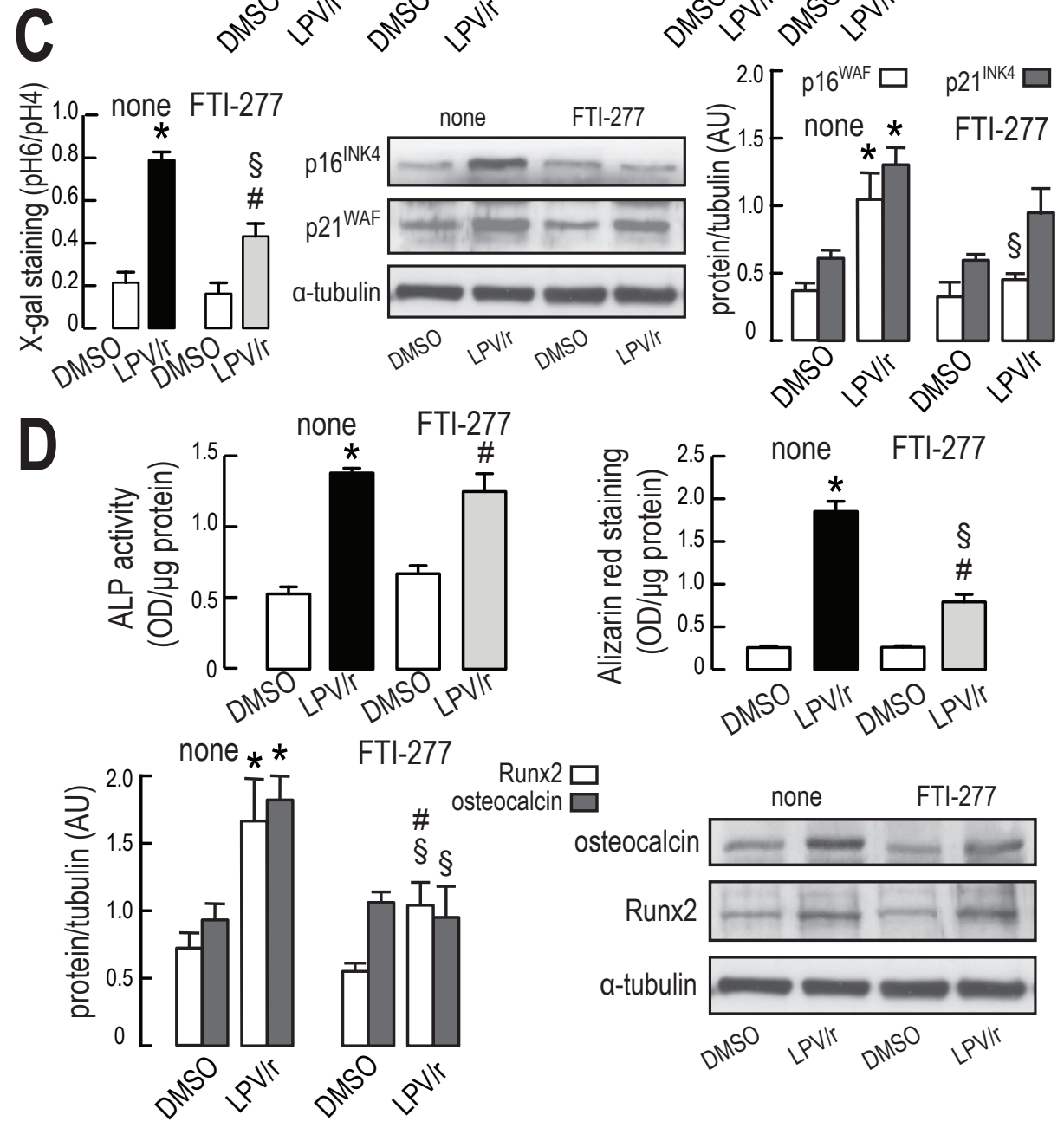
osteocalcin

Runx2

a-tubulin

siRNA none none

etidronate

osteocalcin

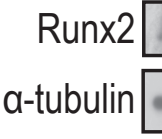

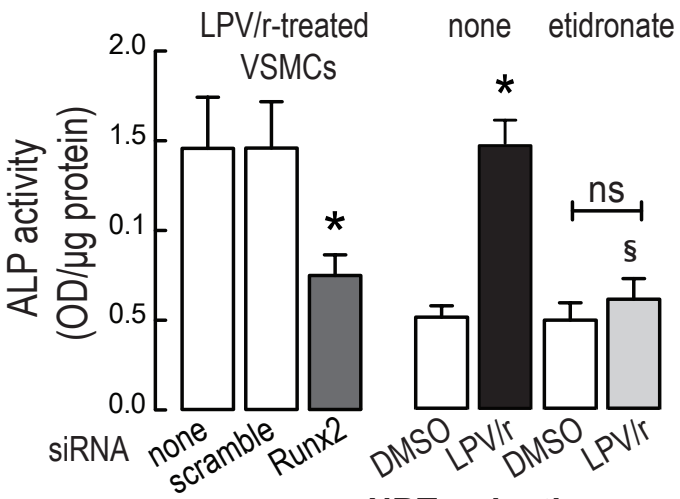

NBT reduction

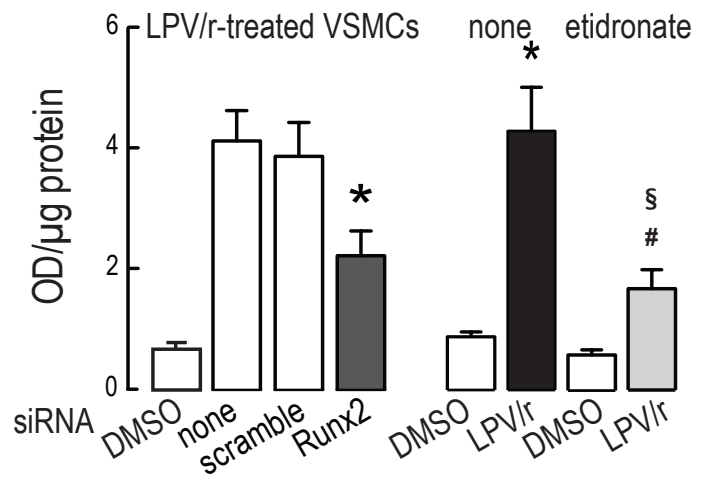

C

prelamin A $\operatorname{lamin} \mathrm{A}$ lamin C

prelamin $\mathrm{A}$

ZMPSTE24

p16 ${ }^{\text {INK4 }}$

p21 WAF

a-tubulin
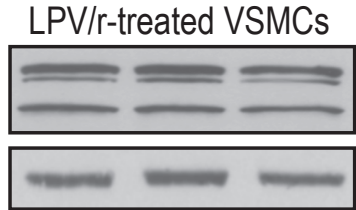

SiRNA none

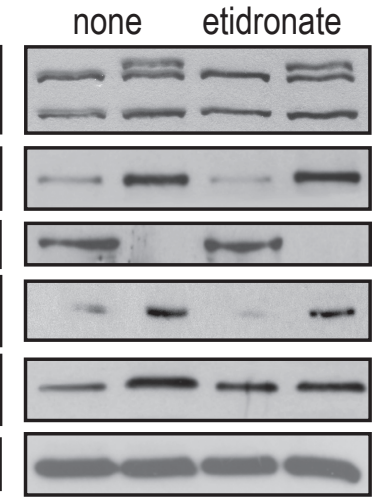
scramble Runt

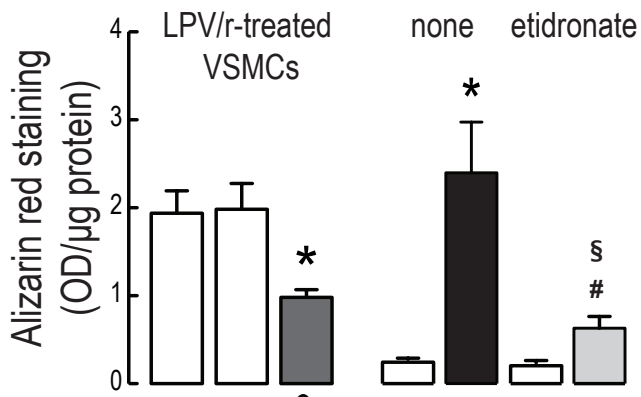

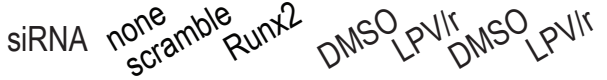

NF-KB activation

NF-kB LPV/r-treated VSMCs p-p65RelA p65RelA siRnA none scamble punte

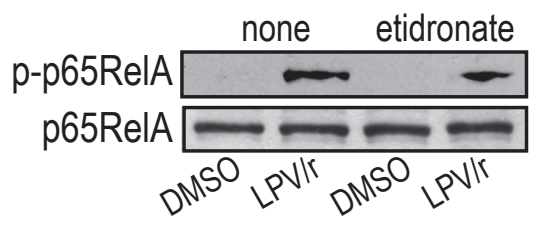

\section{senescence}

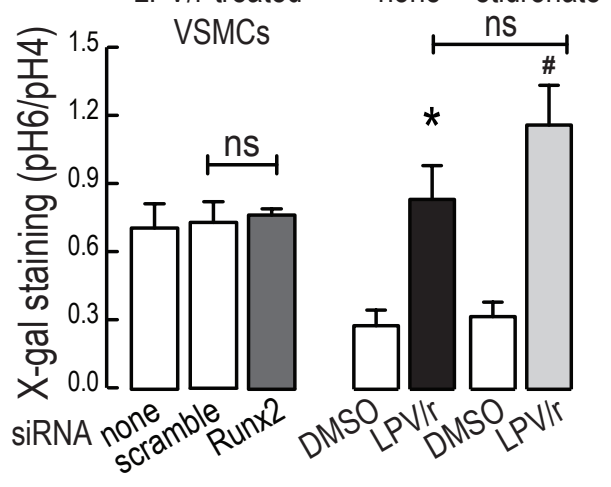

